\title{
Guidelines for Perioperative Care for Pancreatoduodenectomy: Enhanced Recovery After Surgery (ERAS) Recommendations 2019
}

\author{
Emmanuel Melloul $^{1} \cdot$ Kristoffer Lassen $^{2} \cdot$ Didier Roulin $^{1} \cdot$ Fabian Grass $^{1} \cdot$ Julie Perinel $^{3}$. \\ Mustapha Adham ${ }^{3}$ - Erik Björn Wellge ${ }^{4}$. Filipe Kunzler ${ }^{5}$ - Marc G. Besselink ${ }^{6}$. \\ Horacio Asbun ${ }^{5}$ - Michael J. Scott ${ }^{7}$ - Cornelis H. C. Dejong ${ }^{8}$ - Dionisos Vrochides ${ }^{9}$. \\ Thomas Aloia $^{10}$ • Jakob R. Izbicki ${ }^{4}$. Nicolas Demartines ${ }^{1}$
}

Published online: 11 March 2020

(C) Société Internationale de Chirurgie 2020

\begin{abstract}
Background Enhanced recovery after surgery (ERAS) pathways are now implemented worldwide with strong evidence that adhesion to such protocol reduces medical complications, costs and hospital stay. This concept has been applied for pancreatic surgery since the first published guidelines in 2012. This study presents the updated ERAS recommendations for pancreatoduodenectomy (PD) based on the best available evidence and on expert consensus. Methods A systematic literature search was conducted in three databases (Embase, Medline Ovid and Cochrane Library Wiley) for the 27 developed ERAS items. Quality of randomized trials was assessed using the Consolidated Standards of Reporting Trials statement checklist. The level of evidence for each item was determined using the Grading of Recommendations Assessment Development and Evaluation system. The Delphi method was used to validate the final recommendations.

Results A total of 314 articles were included in the systematic review. Consensus among experts was reached after three rounds. A well-implemented ERAS protocol with good compliance is associated with a reduction in medical complications and length of hospital stay. The highest level of evidence was available for five items: avoiding hypothermia, use of wound catheters as an alternative to epidural analgesia, antimicrobial and thromboprophylaxis protocols and preoperative nutritional interventions for patients with severe weight loss $(>15 \%)$.

Conclusions The current updated ERAS recommendations for PD are based on the best available evidence and processed by the Delphi method. Prospective studies of high quality are encouraged to confirm the benefit of current updated recommendations.
\end{abstract}

Nicolas Demartines

Demartines@chuv.ch

1 Department of Visceral Surgery, University Hospital Lausanne (CHUV), University of Lausanne, Rue du Bugnon 46, 1011 Lausanne, Switzerland

2 Department of Hepatobiliary and Pancreatic Surgery, Oslo University Hospital, Oslo, Norway

3 Service de chirurgie Digestive, Hôpital Edouard Herriot, Hospices Civils De Lyon, Lyon, France

4 Department of General, Visceral and Thoracic Surgery, University Medical Centre Hamburg-Eppendorf, 20246 Hamburg, Germany
5 Division of Hepatobiliary and Pancreas Surgery, Miami Cancer Institute, Miami, FL, USA

6 Department of Surgery, Amsterdam UMC, University of Amsterdam, Amsterdam, The Netherlands

7 Royal Surrey County Hospital NHS Foundation Trust, Guildford, UK

8 Departments of Surgery, Maastricht University, Maastricht, The Netherlands

9 Division of Hepatopancreatobiliary Surgery, Department of Surgery, Carolinas Medical Center, Charlotte, NC, USA

10 Department of Surgical Oncology, The University of Texas MD Anderson Cancer Center, Houston, TX, USA 


\section{Introduction}

Enhanced recovery after surgery (ERAS) is a multimodal pathway that has been widely introduced to reduce the surgical stress and improve recovery after major surgery. It is now validated in many types of surgery since it reduces postoperative medical complications, hospital stay and costs [1-3]. First guidelines for pancreatoduodenectomy (PD) were published in 2012 [4]. A recent meta-analysis confirmed the positive impact of ERAS on postoperative recovery after PD [5].

The present systematic review elaborates the updated ERAS Society guidelines for enhanced recovery after PD by systematic review of the literature and expert consensus with the Delphi method.

\section{Methods}

\section{Literature search and data selection}

A systematic literature search was conducted with the assistance of a medical librarian in four databases (Embase, PubMed, Medline Ovid and Cochrane Library Wiley) for the 27 developed items. Terms related to pancreatoduodenectomy were combined with terms related to each item. Thesaurus terms and free terms were identified after analysis of the 2012 guideline [4]. The period search was from January 2000 to December 2018. Only full-text articles in English were analyzed. Eligible articles included metaanalyses, randomized controlled trials (RCTs) or prospective cohort studies with control group. Retrospective series were considered only if data of better quality could not be identified. For the items where no specific data in pancreatic surgery were available, results were extrapolated from other types of abdominal surgery. Following the searches, all identified citations were collated into a citation management software (Endnote X8). The quality of RCTs included was assessed using the Consolidated Standards of Reporting Trials (CONSORT) statement checklist [6]. The level of evidence for each item was determined using the Grading of Recommendations Assessment Development and Evaluation (GRADE) system, in which the level of evidence was classified as high, moderate, low or very low [7]. The research team (EM, ND) made a final decision on inclusion of a study or not and was responsible for drafting the first manuscript.

\section{Modified delphi process}

As previously performed for the ERAS guidelines for liver surgery, a three-round Web-based Delphi approach was used in this consensus process [8,9]. Each expert was asked to write one up to four items chapters and a recommendation according to the literature search. Once all recommendations were written, the research team responsible for editing the manuscript distributed the draft to all authors. Each expert was asked to comment and edit the recommendations for every ERAS item using the text editor track change system. The research team served in the role of facilitator, undertaking the synthesis between rounds. The process of synthesis included discussion among the research team, exploring all expert disagreements and comments, before synthesized recommendations were drafted for each subsequent round.

\section{Results}

The electronic search yielded 8368 potential studies. A total of 314 articles were included in the systematic review. The selection process according to PRISMA guidelines is displayed in Fig. 1. The summary and grading of recommendations with their respective level of evidence are depicted in Table 1.

\section{Evidence and recommendations}

\section{Preoperative counseling}

The preoperative visit is the best moment to inform patients about surgery and anesthesia. This review did not find dedicated studies on preoperative counseling for PD; however, the results of one RCT and three reviews/retrospective studies in surgery or anesthesia showed that preoperative counseling reduces fear and anxiety with a positive impact on patient recovery and hospital discharge [10-14]. Multimedia information seems superior to only spoken information, with or without leaflet [11].

Summary and recommendation: Patients should receive dedicated preoperative counseling, preferably with multimedia informational materials rather than only spoken information with or without an educational pamphlet.

\section{Evidence level: Moderate \\ Grade of recommendation: Weak}

\section{Prehabilitation}

There is emerging evidence that avoiding sarcopenia and loss of visceral adipose tissue before major surgery may contribute to improved postoperative outcome. Therefore, a multimodal prehabilitation program, including physical exercise, nutritional supplements and anxiety reduction strategies, can optimize the patient's body 
Fig. 1 PRISMA flowchart

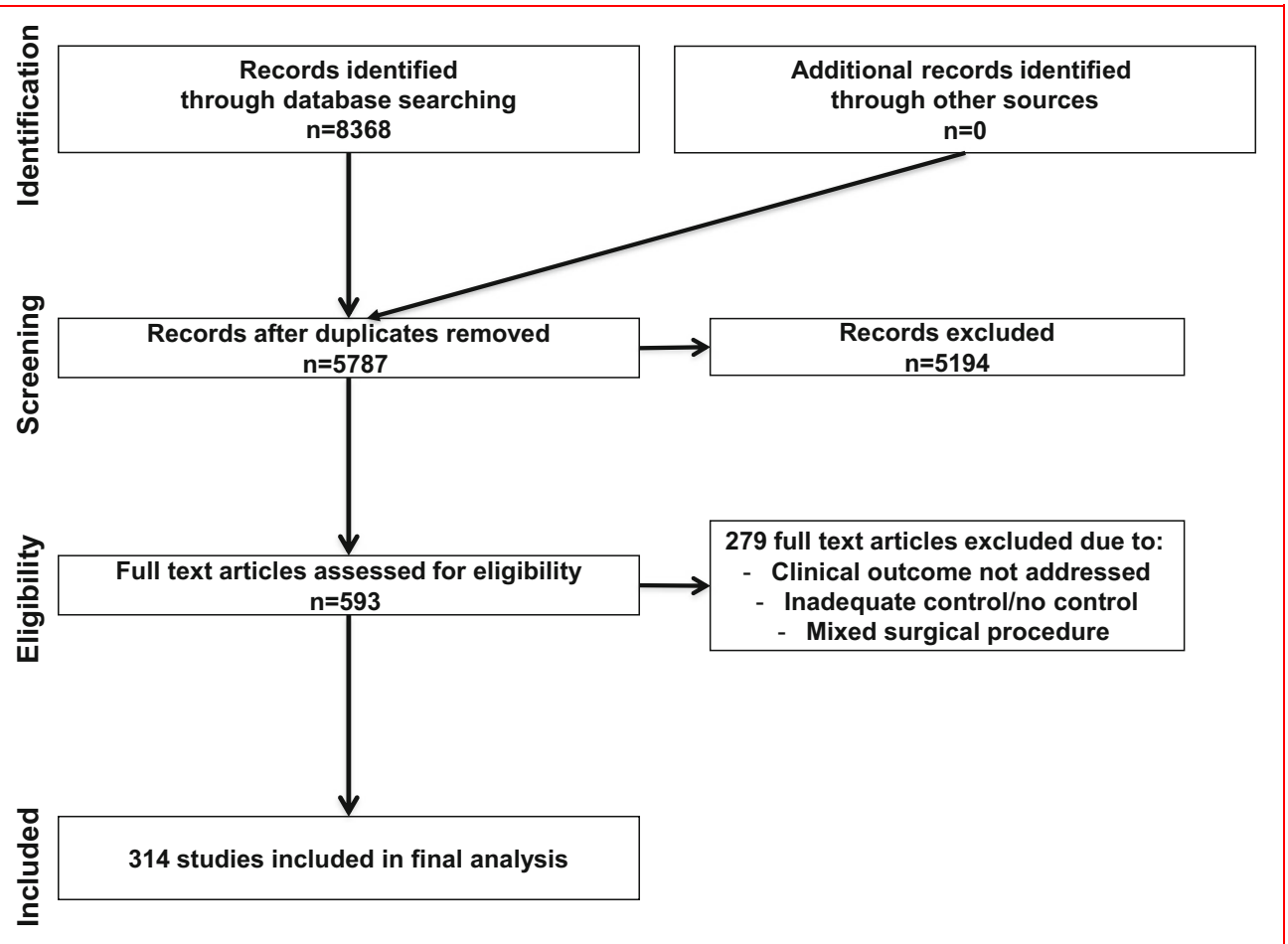

composition and physical performance. Prehabilitation program for colorectal surgery enhanced patient functional status, reduced postoperative morbidity and shortened hospital stay; however, evidence after PD procedure is lacking [15]. Nevertheless, in a recent RCT carried out in high-risk patients undergoing major gastrointestinal surgery, a prehabilitation program enhanced aerobic capacity and reduced postoperative complications [16]. To be effective, a prehabilitation program should be initiated at least 3-6 weeks before surgery.

Summary and recommendation: A prehabilitation program initiated 3-6 weeks before major surgery seems to reduce postoperative complications and preserve functional status. More data are needed to confirm its benefit in PD patients.

Evidence level: Moderate

Grade of recommendation: Strong

\section{Preoperative biliary drainage}

An increased number of patients with pancreatic ductal carcinoma require neoadjuvant chemotherapy, and in those particular cases, biliary drainage is a necessity and not an option. Complication related to preoperative biliary stenting has been assessed in 12 meta-analyses [17-28]. Preoperative drainage is associated with increased postoperative complications, including wound complications, but without impact on mortality $[18-21,23,25,26,28]$. These results are confirmed by a review of the NSQIP database, which found increased risk of sepsis and wound infections after drainage without impact on mortality [29]. One of the meta-analyses did not demonstrate any postoperative adverse effects after drainage [17]. Moreover, one single meta-analysis showed less major adverse effects with preoperative biliary drainage [24].

Two Cochrane reviews explored this topic [27]; the second review from 2012 that included four RCTs focused on percutaneous transhepatic biliary drainage and two on endoscopic stenting. The risk of bias was rated as high in all trials. These studies consistently observed no difference in postoperative mortality, but morbidity rates were higher in preoperative biliary drainage. Analyzing $1500 \mathrm{PD}$, the Verona group observed neither increased major complications nor mortality after biliary drainage, but higher surgical site infection (SSI) rates [30]. Resection should be performed without prior endoscopic stenting for asymptomatic patients with bilirubin level below $250 \mu \mathrm{mol} / 1$ (15 mg/dl) [31]. We have presently no level 1 evidence for those with higher serum bilirubin levels

According to a recent meta-analysis, percutaneous biliary drainage seems to be inferior because it offers no clear advantage to the other options in terms of postoperative complications while causing significant discomfort to patients. Neither preoperative biliary drainage with plastic stent nor metallic stent was superior in terms of postoperative complications [32]. 
Table 1 Summary of updated ERAS recommendations for PD for each item and their respective level of evidence and grade

\begin{tabular}{|c|c|c|c|}
\hline ERAS item & Summary & $\begin{array}{l}\text { Evidence } \\
\text { level }\end{array}$ & Grade of recommendation \\
\hline $\begin{array}{l}\text { 1. Preoperative } \\
\text { counseling }\end{array}$ & $\begin{array}{l}\text { Patients should receive dedicated preoperative } \\
\text { counseling, preferably with multimedia } \\
\text { informational materials rather than only spoken } \\
\text { information with or without an educational } \\
\text { pamphlet. }\end{array}$ & Moderate & Weak \\
\hline 2. Prehabilitation & $\begin{array}{l}\text { A prehabilitation program initiated } 3-6 \text { weeks before } \\
\text { major surgery seems to reduce postoperative } \\
\text { complications and preserve functional status. }\end{array}$ & Moderate & Strong \\
\hline $\begin{array}{l}\text { 3. Preoperative biliary } \\
\text { drainage }\end{array}$ & $\begin{array}{l}\text { Preoperative biliary drainage increases postoperative } \\
\text { complications without change in mortality rates. } \\
\text { Therefore, preoperative biliary drainage should be } \\
\text { avoided unless decompression is needed (bilirubin } \\
\text { level above } 250 \mu \mathrm{mol} / 1 \text {, preoperative episodes of } \\
\text { cholangitis, neoadjuvant treatment). }\end{array}$ & High & Strong \\
\hline $\begin{array}{l}\text { 4. Preoperative smoking } \\
\text { and alcohol } \\
\text { consumption }\end{array}$ & $\begin{array}{l}\text { At least } 4 \text { weeks of preoperative smoking cessation is } \\
\text { suggested to decrease wound healing complications } \\
\text { and respiratory complications. Benefits of alcohol } \\
\text { abstention for moderate users have not been } \\
\text { documented. }\end{array}$ & $\begin{array}{l}\text { Smoking cessation: } \\
\text { moderate; alcohol } \\
\text { cessation for moderate } \\
\text { users: low } \\
\text { Alcohol cessation for high } \\
\text { users: high }\end{array}$ & Strong \\
\hline 5. Preoperative nutrition & $\begin{array}{l}\text { Preoperative nutritional intervention is recommended } \\
\text { for patients with severe weight loss (i.e., }>15 \% \\
\text { weight loss or BMI- }<18.5 \mathrm{~kg} / \mathrm{m}^{2} \text { secondary to } \\
\text { their disease). } \\
\text { Preoperative nutritional status based on BMI and } \\
\text { weight loss based on self-reported pre-morbid } \\
\text { weight and weight scaling upon admission is } \\
\text { recommended }\end{array}$ & $\begin{array}{l}>15 \% \text { weight loss: high } \\
\text { Moderate }\end{array}$ & $\begin{array}{l}\text { Strong } \\
\text { Weak }\end{array}$ \\
\hline $\begin{array}{l}\text { 6. Perioperative oral } \\
\text { immunonutrition }\end{array}$ & Immunonutrition is not recommended & High & Strong \\
\hline $\begin{array}{l}\text { 7. Preoperative fasting } \\
\text { and treatment with } \\
\text { carbohydrates }\end{array}$ & $\begin{array}{l}\text { Preoperative fasting can be limited to } 6 \mathrm{~h} \text { for solids } \\
\text { and } 2 \mathrm{~h} \text { for liquids in patients without specific risk } \\
\text { factors (i.e., gastric outlet obstruction, diabetes with } \\
\text { severe neuropathy) } \\
\text { Carbohydrate loading is recommended }\end{array}$ & $\begin{array}{l}\text { Moderate } \\
\text { Moderate }\end{array}$ & $\begin{array}{l}\text { Strong } \\
\text { Strong }\end{array}$ \\
\hline $\begin{array}{l}\text { 8. Pre-anesthetic } \\
\text { medication }\end{array}$ & $\begin{array}{l}\text { Pharmacological anxiolytics should be avoided as } \\
\text { much as possible, particularly in the elderly to } \\
\text { avoid postoperative cognitive dysfunction } \\
\text { Opioid sparing multimodal pre-anesthetic medication } \\
\text { can be with a combination of acetaminophen } 1 \mathrm{~g} \\
\text { and a single dose of gabapentinoid } \\
\text { NSAIDS or selective COX } 2 \text { inhibitor can be initiated } \\
\text { appropriately in the postoperative period if good } \\
\text { renal function }\end{array}$ & $\begin{array}{l}\text { Moderate } \\
\text { Moderate } \\
\text { Moderate }\end{array}$ & $\begin{array}{l}\text { Strong } \\
\text { Strong } \\
\text { Strong }\end{array}$ \\
\hline $\begin{array}{l}\text { 9. Anti-thrombotic } \\
\text { prophylaxis }\end{array}$ & $\begin{array}{l}\text { LMWH or UFH reduces the risk of VTE } \\
\text { complications and should be started } 2-12 \mathrm{~h} \text { before } \\
\text { surgery and continued until hospital discharge. } \\
\text { Extended thromboprophylaxis ( } 4 \text { weeks) is advised } \\
\text { after PD for cancer. Concomitant use of epidural } \\
\text { analgesia necessitates close adherence to safety } \\
\text { guidelines } \\
\text { Mechanical measures are advised in addition to } \\
\text { chemical thromboprophylaxis }\end{array}$ & $\begin{array}{l}\text { High } \\
\text { Low }\end{array}$ & $\begin{array}{l}\text { Strong } \\
\text { Weak }\end{array}$ \\
\hline
\end{tabular}


Table 1 continued

\begin{tabular}{|c|c|c|c|}
\hline ERAS item & Summary & $\begin{array}{l}\text { Evidence } \\
\text { level }\end{array}$ & Grade of recommendation \\
\hline $\begin{array}{l}\text { 10. Antimicrobial } \\
\text { prophylaxis and skin } \\
\text { preparation }\end{array}$ & $\begin{array}{l}\text { Single-dose intravenous antibiotics should be } \\
\text { administered less than } 60 \text { min before skin incision. } \\
\text { Repeated intraoperative doses are necessary } \\
\text { depending on the half-life of the drug and duration } \\
\text { of the procedure. Postoperative "prophylactic" } \\
\text { antibiotics are not recommended but could be } \\
\text { considered therapeutic if bile culture is positive. } \\
\text { Intraoperative bile cultures should be performed } \\
\text { routinely in patients with an endobiliary stent } \\
\text { Alcohol-based preparations are recommended as a } \\
\text { first option for skin preparation. Wound protectors } \\
\text { may help to reduce the rate of SSI }\end{array}$ & $\begin{array}{l}\text { High } \\
\text { Moderate }\end{array}$ & $\begin{array}{l}\text { Strong } \\
\text { Strong }\end{array}$ \\
\hline 11. Epidural analgesia & $\begin{array}{l}\text { Thoracic epidural anesthesia for open PD in the ERAS } \\
\text { setting offers improved analgesia compared to } \\
\text { intravenous opiates, with improving return of } \\
\text { postoperative intestinal function and reducing } \\
\text { pulmonary complications }\end{array}$ & Moderate & Strong \\
\hline $\begin{array}{l}\text { 12. Postoperative } \\
\text { intravenous and per } \\
\text { oral analgesia }\end{array}$ & $\begin{array}{l}\text { A postoperative multimodal opioid sparing strategy } \\
\text { tailored to each institutional expertise is strongly } \\
\text { recommended }\end{array}$ & Moderate & Strong \\
\hline $\begin{array}{l}\text { 13. Wound catheter and } \\
\text { transversus abdominis } \\
\text { plane (TAP) block }\end{array}$ & $\begin{array}{l}\text { Continuous wound infiltration through preperitoneal } \\
\text { catheter is an alternative to epidural for open PD }\end{array}$ & High & Strong \\
\hline $\begin{array}{l}\text { 14. Postoperative nausea } \\
\text { and vomiting (PONV) } \\
\text { prophylaxis }\end{array}$ & $\begin{array}{l}\text { All patients should receive PONV prophylaxis. } \\
\text { Patients with } 2 \text { or more risk factors for PONV (i.e., } \\
\text { female, non-smoking status, history of PONV or } \\
\text { motion sickness, and postoperative opioid use) } \\
\text { should receive a combination of two antiemetics as } \\
\text { prophylaxis. Patients with three to four risk factors } \\
\text { should receive two to three antiemetics }\end{array}$ & Moderate & Strong \\
\hline $\begin{array}{l}\text { 15. Avoiding } \\
\text { hypothermia }\end{array}$ & $\begin{array}{l}\text { Clinically relevant hypothermia starts at } 36{ }^{\circ} \mathrm{C} \text { with } \\
\text { regard to major adverse outcomes. Active warming } \\
\text { (forced-air or circulating-water garment systems) } \\
\text { should be initiated before the induction of } \\
\text { anesthesia if the patient's oral temperature is below } \\
36{ }^{\circ} \mathrm{C} \text {. Intraoperatively, active warming and } \\
\text { supportive measures should continue to maintain } \\
\text { temperature above } 36{ }^{\circ} \mathrm{C} \text {. Postoperatively, patients } \\
\text { should be discharged from the post-anesthesia care } \\
\text { unit if temperature is above } 36{ }^{\circ} \mathrm{C}\end{array}$ & High & Strong \\
\hline $\begin{array}{l}\text { 16. Postoperative } \\
\text { glycemic control }\end{array}$ & $\begin{array}{l}\text { Current data support an association between elevated } \\
\text { blood glucose and adverse clinical outcomes in } \\
\text { patients with and without diabetes. The optimal } \\
\text { glycemic target during the perioperative period } \\
\text { remains unclear. Glucose levels should be } \\
\text { maintained as close to normal as possible without } \\
\text { compromising patient safety. Perioperative } \\
\text { treatments that reduce insulin resistance without } \\
\text { causing hypoglycemia are recommended. Strong } \\
\text { evidence to support the non-inferiority of strict } \\
\text { glycemic control (blood glucose levels within } \\
\text { normal and narrow range) is lacking }\end{array}$ & Moderate & Strong \\
\hline $\begin{array}{l}\text { 17. Nasogastric } \\
\text { intubation }\end{array}$ & $\begin{array}{l}\text { Maintenance of nasogastric intubation after surgery is } \\
\text { not recommended }\end{array}$ & Moderate & Strong \\
\hline
\end{tabular}


Table 1 continued

\begin{tabular}{|c|c|c|c|}
\hline ERAS item & Summary & $\begin{array}{l}\text { Evidence } \\
\text { level }\end{array}$ & Grade of recommendation \\
\hline 18. Fluid balance & $\begin{array}{l}\text { Avoidance of fluid overload in patients within an } \\
\text { enhanced recovery protocol results in improved } \\
\text { outcome. A goal-directed fluid therapy algorithm } \\
\text { using intra- and postoperative noninvasive } \\
\text { monitoring is associated with reduced perioperative } \\
\text { fluid administration and potentially improved } \\
\text { outcome }\end{array}$ & Moderate & Strong \\
\hline $\begin{array}{l}\text { 19. Perianastomotic } \\
\text { drainage }\end{array}$ & $\begin{array}{l}\text { Early drain removal at } 72 \mathrm{~h} \text { is recommended in } \\
\text { patients with amylase content in drain }<5000 \mathrm{U} / \mathrm{L} \\
\text { on POD1 }\end{array}$ & $\begin{array}{l}\text { Selective no-drain regimen: } \\
\text { moderate } \\
\text { Early removal: high }\end{array}$ & $\begin{array}{l}\text { Selective no-drain regimen: } \\
\text { weak } \\
\text { Early removal: strong }\end{array}$ \\
\hline $\begin{array}{l}\text { 20. Somatostatin } \\
\text { analogues }\end{array}$ & $\begin{array}{l}\text { The systematic use of somatostatin analogues to } \\
\text { reduce clinically significant POPF cannot be } \\
\text { recommended because trial results have not been } \\
\text { validated yet }\end{array}$ & Moderate & Weak \\
\hline 21. Urinary drainage & $\begin{array}{l}\text { In patients with wound catheters or intravenous } \\
\text { analgesia, urinary catheters can be removed on the } \\
\text { first postoperative day or as soon as the patient is } \\
\text { independently ambulant. All other patients should } \\
\text { leave the operative room with an indwelling urinary } \\
\text { catheter }\end{array}$ & Low & Strong \\
\hline $\begin{array}{l}\text { 22. Delayed gastric } \\
\text { emptying }\end{array}$ & $\begin{array}{l}\text { DGE after PD is mainly associated with postoperative } \\
\text { complications as POPF and intra-abdominal } \\
\text { infections. There are no acknowledged strategies to } \\
\text { prevent DGE, although a timely diagnosis and } \\
\text { treatment of intra-abdominal complications might } \\
\text { reduce the duration of DGE. In patients with } \\
\text { prolonged DGE, administration of artificial } \\
\text { nutrition can improve outcome }\end{array}$ & Low & Strong \\
\hline $\begin{array}{l}\text { 23. Stimulation of bowel } \\
\text { movement }\end{array}$ & $\begin{array}{l}\text { Chewing gum is safe and may accelerate bowel } \\
\text { recovery } \\
\text { Alvimopan at a dose of } 6 \text { to } 12 \mathrm{mg} \text { BID accelerates } \\
\text { postoperative ileus recovery } \\
\text { Mosapride appears to improves ileus } \\
\text { Metoclopramide and bromopride have no effect on } \\
\text { ileus } \\
\text { Other drugs (ghrelin receptor antagonists, } \\
\text { dihydroergotamine and neostigmine, erythromycin) } \\
\text { appear to have no effect in postoperative ileus and } \\
\text { their routine used is not justified }\end{array}$ & $\begin{array}{l}\text { Moderate } \\
\text { Moderate } \\
\text { Very low } \\
\text { Very low } \\
\text { Very low (ghrelin receptor } \\
\text { antagonists, } \\
\text { dihydroergotamine and } \\
\text { neostigmine); } \\
\text { Moderate } \\
\text { (erythromycin) }\end{array}$ & $\begin{array}{l}\text { Weak } \\
\text { Weak } \\
\text { Weak } \\
\text { Weak } \\
\text { Weak (ghrelin receptor } \\
\text { antagonists, } \\
\text { dihydroergotamine and } \\
\text { neostigmine); } \\
\text { Strong (erythromycin) }\end{array}$ \\
\hline $\begin{array}{l}\text { 24. Postoperative } \\
\text { artificial nutrition }\end{array}$ & $\begin{array}{l}\text { Patients should be allowed a normal diet after surgery } \\
\text { without restrictions according to tolerance. } \\
\text { Artificial nutrition should be considered as an } \\
\text { individual approach according to the nutritional } \\
\text { status assessment. The enteral route should be } \\
\text { preferred }\end{array}$ & Moderate & Strong \\
\hline $\begin{array}{l}\text { 25. Early and scheduled } \\
\text { mobilization }\end{array}$ & $\begin{array}{l}\text { Early and active mobilization should be encouraged } \\
\text { from day } 0 \text {. No evidence for specific protocol or } \\
\text { daily targets is available for PD }\end{array}$ & Low & Strong \\
\hline $\begin{array}{l}\text { 26. Minimal invasive } \\
\text { surgery }\end{array}$ & $\begin{array}{l}\text { LPD should only be performed in highly experienced, } \\
\text { high-volume centers, and only within strict } \\
\text { protocols. Safety is still a concern. Future studies } \\
\text { should address the benefit of LPD in high-volume } \\
\text { centers } \\
\text { Currently, there is insufficient evidence to assess } \\
\text { RAPD and it cannot be recommended. Prospective } \\
\text { studies from high-volume centers are needed }\end{array}$ & $\begin{array}{l}\text { Moderate } \\
\text { Low }\end{array}$ & $\begin{array}{l}\text { Strong } \\
\text { Weak }\end{array}$ \\
\hline
\end{tabular}


Table 1 continued

\begin{tabular}{|c|c|c|c|}
\hline ERAS item & Summary & $\begin{array}{l}\text { Evidence } \\
\text { level }\end{array}$ & Grade of recommendation \\
\hline 27. Audit & $\begin{array}{l}\text { Regular audit and feedback based on an electronic } \\
\text { database are essential components of ERAS and are } \\
\text { associated with improved compliance and outcome }\end{array}$ & Moderate & Strong \\
\hline
\end{tabular}

Summary and eecommendation: Preoperative biliary drainage increases postoperative complications without change in mortality rates. Therefore, preoperative biliary drainage should be avoided unless decompression is needed (bilirubin $>250 \mu \mathrm{mol} / \mathrm{l}$, cholangitis, pruritus, neoadjuvant treatment).

Evidence Level: High

Recommendation grade for no preoperative drainage: Strong

\section{Preoperative smoking and alcohol consumption}

Two studies including 721 and 17,564 PD patients showed that smoking was a significant predictor of primary delayed gastric emptying and grade $\mathrm{C}$ pancreatic fistula, respectively $[33,34]$.

Randomized trials reported an absolute risk reduction in complications of $20-30 \%$ when smoking was stopped 4-8 weeks preoperatively [35, 36]. However, a randomized trial of short-term (15 days) smoking cessation showed no significant differences in overall complication rates [37]. The optimal length of time of abstinence necessary to benefit previous smokers remains unclear.

Alcohol consumption was associated with increased postoperative complications like surgical site infection (SSI), pulmonary complications, prolonged length of stay (LoS) and admission to intensive care unit [38]. High alcohol consumption was associated with increased postoperative mortality, whereas low-to-moderate alcohol consumption did not appear to increase postoperative complications [38].

A univariate analysis of 539 PD showed no correlation between alcohol and pancreatic fistula [39]. A meta-analysis showed that preoperative alcohol cessation significantly decreased postoperative complications, but 30-day mortality and LoS were not affected [40].

Summary and recommendation: At least 4 weeks of preoperative smoking cessation is suggested to decrease wound healing complications and respiratory complications. Benefits of alcohol abstention for moderate users have not been documented.
Evidence level: Smoking cessation: moderate; alcohol cessation for moderate users: low; alcohol cessation for high users: high

\section{Grade of recommendation: Strong}

\section{Preoperative nutrition}

Based on pre-morbid, self-reported weight, $5 \%$ weight loss has been demonstrated to be a significant predictor of complications [41]. The majority of patients with pancreatic malignancy had significant weight loss before surgery [42]. This emphasizes the need for supplemental nutrition, trying to restore baseline nutritional status prior to complex operations. Nutritional interventions (parenteral, enteral or oral/sip feeds) are often recommended for patients with significant weight loss planned for major operations, and these interventions will usually result in weight gain $[43,44]$. It remains unproven that preoperative nutritional support reduces complication rates or enhances recovery [45]. A recent evaluation of several established screening tools for malnutrition demonstrated the absence of prognostic power in pancreatic surgery [46].

Nutritional support is recommended for patients with weight loss $>15 \%$ or BMI drop to $<18.5 \mathrm{~kg} / \mathrm{m}^{2}$ [47]. This may improve their sense of well-being. For patients with moderate weight loss, preoperative nutrition support is recommended by the ESPEN guidelines from 2006 to 2017, but this is based on uncontrolled or unblinded trials, or using surrogate endpoints [43, 44]. Of 35 randomized controlled trials included in latest ESPEN recommendation of 2017, none were published later than 2004 [44]. In malnourished patients requiring nutritional support before surgery, the enteral feeding through a nasogastric or nasojejunal feeding tube should be the preferred route of administration rather than total parenteral nutrition. In severe cases, surgery might be postponed to obtain adequate nutritional status at the time of surgery.

\section{Summary and recommendations:}

- Preoperative nutritional intervention (e.g., nasogastric or nasojejunal feeding tube) is recommended for 
patients with severe weight loss, not as general measure (i.e., $>15 \%$ weight loss or BMI $<18.5 \mathrm{~kg} / \mathrm{m}^{2}$ ).

\section{- Level of evidence:}

- $>15 \%$ weight loss: High

\section{- Grade of recommendation: Strong}

- Preoperative nutritional assessment expanding beyond calculation of BMI and weight loss based on selfreported pre-morbid weight and weight scaling upon admission is not warranted.

- Level of evidence: Moderate

- Grade of recommendation: Weak

\section{Perioperative oral immunonutrition (IN)}

Pancreatic cancer patients tend to have high levels of pro-inflammatory cytokines as well as malnutrition and cachexia [48-50]. Through its potential to modulate the perioperative inflammatory response, IN containing arginine, glutamine, $\omega-3$ fatty acids and nucleotides has been associated in several meta-analyses with decreased complication rates and LoS after major gastrointestinal cancer surgery [46, 51-55]. However, study heterogeneity was high, and optimal timing for administration debated [56-58]. Specific evidence on IN in pancreatic surgery is scarce [59]. An RCT including $>200$ patients did not demonstrate advantage of routine postoperative IN in elective upper gastrointestinal surgery patients [57]. Three recent RCTs demonstrated a favorable effect of either preor perioperative enteral IN on systemic immunity in PD patients [60-62].

The potential benefits of different combinations of immunonutrients in major abdominal surgery were evaluated recently [63]. IN compared with control groups reduced overall and infectious complications in 83 RCTs with 7116 patients (grade of evidence low to moderate). Of note, these effects vanished after excluding trials at high risk of bias. Non-industry-funded trials did not display positive effects for overall complications, whereas industry-funded reported large effects [56-58].

Summary and recommendation: Immunonutrition is not recommended.

Evidence level: High

Grade of recommendation: Strong

7. Preoperative fasting and preoperative treatment with carbohydrates

The ESPEN guidelines recommend clear fluids to be allowed until $2 \mathrm{~h}$ prior to anesthesia induction and until $6 \mathrm{~h}$ before induction for solid foods [44]. This excludes patients with risk factors for aspiration like in gastric outlet obstruction or in diabetics with severe neuropathy. It should be emphasized that most studies excluded patients with gastroduodenal pathology.

Preoperative carbohydrates intake aims to improve metabolic conditioning to saturate liver glycogen stores immediately before surgery, thus avoiding the glycogendepleted state caused by an overnight fasting [64]. This is achieved by a carbohydrate-rich solution taken orally the evening before and $2 \mathrm{~h}$ prior to surgery. The safety of carbohydrate loading is well documented. Postoperative insulin resistance is attenuated, as is thirst and anxiety [65]. These drinks are safe and cheap and improve the avoidance of dehydration, but a significant effect on postoperative complication remains to be demonstrated [66].

\section{Summary and recommendations}

- Preoperative fasting can be limited to $6 \mathrm{~h}$ for solids and $2 \mathrm{~h}$ for liquids in patients without risk factors (i.e., gastric outlet obstruction, diabetes with neuropathy)

- Level of evidence: Moderate

- Grade of recommendation: Strong

- Carbohydrate loading is safe and may have some beneficial effects.

- Level of evidence: Moderate

- Grade of recommendation: Strong

\section{Pre-anesthetic medication}

A key strategy to reduce patient anxiety is a comprehensive preoperative communication and education program with consistent and clear messages so that patients understand the surgical pathway and engage actively in their recovery [67]. For patients undergoing procedures such as insertion of epidural catheters immediately prior to surgery, small doses of intravenous midazolam (1-2 mg) may be given to ameliorate anxiety with minimal residual effect [68].

The aim of starting a multimodal analgesic strategy prior to surgery is to reduce the need for opiates and their side effects like sedation, nausea and vomiting. Where approved, paracetamol (Acetaminophen) $1 \mathrm{~g}$ can be given as either tablets or soluble solution prior to surgery. NSAIDS are usually part of multimodal analgesia within ERAS pathways unless contraindicated (risk of gastrointestinal side effects, asthma or renal insufficiency). Nonselective and selective COX 2 inhibitors are available, have no effect on platelet function and reduce gastritis incidence and renal insufficiency. The use of gabapentinoids in surgical patients has shown a benefit in acute pain relief [69]. 
Optimal dosing has not yet been established, but a single dose between 75 and $300 \mathrm{mg}$ of pregabalin preoperatively produced a 24-h reduction in opioid requirement. However, it is used with caution in elderly or in renal impairment patients, as higher doses can lead to sedation, visual disturbance or psychomotor issues affecting postoperative mobilization [70].

\section{Summary and recommendation:}

- Pharmacological anxiolytics should be avoided as much as possible, particularly in elderly to avoid postoperative cognitive dysfunction.

- Level of evidence: Moderate

- Recommendation grade: Strong

- Opioid sparing multimodal pre-anesthetic medication combines acetaminophen $1 \mathrm{~g}$ and a single dose of gabapentinoid.

- Level of evidence: Moderate

- Recommendation grade: Strong

- NSAIDS or selective COX 2 inhibitor initiated postoperatively, if good renal function.

- Level of evidence: Moderate

- Recommendation grade: Strong

\section{Anti-thrombotic prophylaxis}

PD is an independent risk factor for postoperative deep venous thrombosis (DVT) and pulmonary embolism (PE). It concerns a majority of elderly cancer patients at a high risk of venous thromboembolism (VTE) with complications [71, 72].

The ASCO guidelines update recommended systematic postoperative thromboprophylaxis up to 4 weeks in oncologic patients undergoing major abdominal surgery with high-risk features [73]. The low molecular weight heparin (LMWH) or unfragmented heparin (UFH) treatment should be started 2-12 h before surgery [72]. A recent Cochrane review reported no difference between perioperative LMWH, UFH and fondaparinux on mortality, VTE outcomes and bleeding (minor or major). LMWH is preferable because of compliance (once-daily administration) [74]. The additional use of compressive stockings and intermittent pneumatic compression devices is recommended [75].

In a comparative cohort study $(n=186)$, PD patients receiving thromboprophylaxis had less postoperative VTE but significantly more postoperative hemorrhages. Minor hemorrhages (no invasive treatment or transfusion) were significantly increased, while major hemorrhage (i.e., requiring concentrated red cell transfusion or hemostasis with interventional radiology or surgery) remained unchanged [76]. A large cohort study $(n=13,771)$ confirmed that the rate of post-pancreatectomy VTE outnumbers hemorrhages [77]. Multivariate analysis identified obesity, age $>75$ years and organ space infection as risk factors for late VTE.

Combined perioperative thromboprophylaxis and epidural analgesia is safe if placement or removal of catheter is delayed for at least $12 \mathrm{~h}$ after prophylactic LMWH. No additional hemostasis altering medications should be administered because of additive effects. LMWH should resume at least $4 \mathrm{~h}$ after catheter removal [78].

\section{Summary and recommendation:}

- LMWH or UFH reduces the risk of VTE complications and should be started $2-12 \mathrm{~h}$ before surgery and continued until hospital discharge. Extended thromboprophylaxis (4 weeks) is advised after PD for cancer. Concomitant use of epidural analgesia necessitates close adherence to safety guidelines.

- Evidence level: High

- Grade of recommendation: Strong

- Mechanical measures are advised in addition to chemical thromboprophylaxis.

- Evidence level: Low

- Grade of recommendation: Weak

10. Antimicrobial prophylaxis and skin preparation

The reported incidence of SSI after PD ranges between 7 and 17\% [79-81]. It increases LoS, readmission rate and costs $[82,83]$. In addition, SSI may delay postoperative treatment $[84,85]$.

Antimicrobial prophylaxis is recommended in PD patients to reduce infectious complications [86, 87]. The American College of Surgeons (ACS) and Surgical Infection Society recommend a single dose of intravenous cefazolin (cephalosporin of first generation) within $60 \mathrm{~min}$ before surgical incision [86]. An extra dose should be provided every $3-4 \mathrm{~h}$ during surgery to ensure adequate serum and tissue concentrations [88]. Alternative in $\beta$ lactam allergy is clindamycin/vancomycin with gentamicin.

SSI in PD patients is mainly related to bile contamination during surgery, especially in patients after preoperative biliary drainage (PBD) $[89,90]$. PBD is an independent risk factor of SSI and associated with an increased bacteriobilia [91, 92]. One randomized controlled trial concluded that routine PBD increased the rate of overall complications [93]. In this context, two retrospective studies suggested the use of specific antimicrobial prophylaxis based on preoperative bile culture [91, 94]. One 
single RCT compared targeted antimicrobial therapy with standard regimen in hepatobiliary and pancreatic surgery patients with PBD. SSI was significantly decreased in the targeted group with less organ/space SSI and less multiple drug resistant bacteria. Similar results were reported in the PD subgroup in favor of targeted prophylaxis based on bile culture [93].

Several studies reported a concordance between bacteria in intraoperative bile sample and SSI bacteria [91, 95-97]. Enterococcus and Enterobacter are the most frequent pathogens isolated, but Enterococcus is frequently resistant to common antibiotics (penicillins and cephalosporins) [90, 98, 99]. Two studies reported a significant reduction in SSI with piperacillin or piperacillin-tazobactam compared with standard prophylactic antibiotics [96, 99]. More recently, vancomycin and piperacillin-tazobactam were associated with less SSI in PD patients with periampullary tumors [100]. Despite these results, systematic broad spectrum antibioprophylaxis was not recommended due to the low level of evidence. Antibiotics targeted to Enterococcus species in bile contamination remain controversial in PD patients, because it is difficult to prove whether SSIs bacteria caused colonization or infection [95]. To decrease infections, three retrospective studies proposed prolonged perioperative antibiotics until microbiological culture results became available [97, 98, 101]. If bile was positive, treatment was adapted and continued until POD 5 or 10. In two studies, this was associated with reduced SSI [97, 101]. It is associated, however, with an increased risk of antimicrobial resistance, antibiotic colitis and higher costs [102]. The level of evidence remained low due to retrospective design and heterogeneity. In the recent guidelines of ACS and Surgical Infection Society, there is no evidence that antibiotics administration after skin closure decreases SSI risk.

A large multicenter cohort study reported a great variation between institutions in perioperative antibioprophylaxis, type of microorganisms in bile, wound infection cultures and antibiotics resistance [92]. The authors suggested routine intraoperative bile culture during $\mathrm{PD}$ to adapt antibiotherapy in postoperative infections. They also recommend reevaluating antimicrobial prophylaxis for PD based on specific microbiology data to each institution.

The use of oral antibiotic prophylaxis was investigated and is cost-effective and efficient in PD patients. Metronidazole and doxycycline have a fast complete biodisponibility [103]. Doxycycline is excreted in the liver, and bile concentration is higher than systemic. The antibiotic halflife is long enough, and second dose unnecessary, but there are no large studies in PD patients.

Summary and recommendation: Single-dose intravenous antibiotics should be administered less than
$60 \mathrm{~min}$ before skin incision. Repeated intraoperative doses are necessary depending on drug half-life and surgery duration. Postoperative "prophylactic" antibiotics are not recommended but may be considered therapeutic in positive bile culture. Intraoperative bile cultures should be performed routinely in patients with endobiliary stent.

\section{Evidence level: High \\ Grade of recommendation: Strong}

Regarding skin preparation, several RCTs have compared chlorhexidine based with iodine-based antiseptics with no significant difference in outcomes [104]. Alcoholbased preparations are recommended in first intention rather than aqueous preparations to reduce the rate of SSI [105]. There is no evidence to support the superiority of alcohol-containing chlorhexidine to iodine and alcohol skin preparation [106]. One recent RCT compared chlorhexidine gluconate to povidone-iodine in patients undergoing clean-contaminated upper gastrointestinal or hepatobiliary and pancreatic surgery. There was no difference between the two groups for prevention of SSI [107].

To reduce incisional SSIs, several types of wound protectors have been developed. There is no evidence to support the use of adhesive membrane barriers over the skin. The Cochrane review including five studies reported an increased risk of SSI in the case of adhesive drapes [108]. On the other hand, several RCTs reported the efficiency of ring wound protectors to reduce the incidence of incisional SSIs in patients undergoing gastrointestinal surgeries [109, 110]. A recent systematic review and metaanalysis including 14 RCTs reported a significant benefit of dual-ring protector to decrease the rate of SSI in patients undergoing abdominal surgery [111]. The WHO guidelines recommend using wound protector devices in clean-contaminated abdominal surgical procedures. However, the device use should not be prioritized in low-resource settings over other interventions that prevent SSI, because of their scarce availability and associated costs [112].

Summary and recommendation: Alcohol-based preparations are recommended as a first option for skin preparation. Wound protectors may help to reduce the rate of SSI.

\section{Evidence level: Moderate \\ Grade of recommendation: Strong}

\section{Epidural analgesia}

Most data on epidural analgesia have to be extrapolated from historical non-ERAS pathways [113]. The analgesic effect of thoracic epidural analgesia (TEA) for a large open abdominal incision is superior to intravenous opiates according to a meta-analysis and Cochrane reviews 
[114-116]. A Cochrane review also showed that TEA reduced the incidence of gastrointestinal dysfunction after major abdominal surgery [117]. Pulmonary function is improved with TEA as compared to intravenous opiates due to reduced sedation and improved analgesia [118]. In addition to providing effective analgesia, TEA blocks a part of the neuroendocrine stress response for the duration of the block. This leads to reduced protein catabolism and improved protein synthesis provided early feeding in the immediate postoperative period [119-121]. In this group of patients that often have sarcopenia and poor nutritional status prior to surgery, this can have significant benefits.

The major side effects of TEA are urinary retention, motor block and hypotension. This can be reduced by using combined low-dose local anesthetics with low-dose opioids, which offers superior analgesia and avoids the need of higher local anesthetic concentrations, which are more likely to cause motor block [114, 115]. Hypotension can occur despite normal intravascular volume, so it is imperative that there is a hospital protocol to deal with the hypotension to allow the use of low-dose vasopressors to restore afterload and blood pressure. Otherwise, there is often inadvertent fluid overload due to repeated boluses of intravenous fluid. One series using TEA in pancreatic surgery showed that hemodynamic instability was common and leads to increased complications [122].

The largest prospective study on safety of central neuraxial blockade was carried out in the UK and called the NAP 3 Audit [123]. It showed that the risk of permanent injury or death from having a perioperative epidural placed was between 8 and 17 in 100,000. This risk must be weighed up against the benefits of having a TEA.

For spinal anesthesia, no specific data in pancreatic surgery are available. Spinal anesthesia using a combination of local anesthetic with an opioid such as preservativefree diamorphine or morphine can be used in addition to general anesthesia. Although the stress response is reduced only for the duration of the local anesthetic block, there is a significant downstream opioid sparing effect [124]. Patients undergoing laparoscopic surgery will benefit more than those having open surgery where other local anesthetic blocks may be needed in addition to multimodal oral analgesia.

Summary and recommendation: Mid-thoracic epidural anesthesia offers excellent postoperative analgesia and has metabolic effects to reduce the catabolic effects of surgery. A correctly placed catheter with an infusion of low-concentration local anesthetic combined with low-dose opioids improves efficacy and reduces the unwanted side effects of motor block and hypotension due to sympathetic block. TEA run for $48-72 \mathrm{~h}$ postoperatively appears to show maximal benefit providing that MAP is maintained and fluid excess is avoided.
- Thoracic epidural anesthesia for open PD in the ERAS setting offers improved analgesia compared to intravenous opiates, with improving return of postoperative intestinal function and reducing pulmonary complications:

- Level of evidence: Moderate

- Recommendation grade: Strong

12. Postoperative intravenous and per oral analgesia

\section{Paracetamol/acetaminophen}

Paracetamol (Acetaminophen) is effective when given regularly every 4-6 h up to $4 \mathrm{~g}$ per $24 \mathrm{~h}$ although the dose should be reduced in patients with documented liver dysfunction [125]. An alternative to the IV route is oral or rectal, and these are considerably cheaper. However, the intravenous route offers rapid onset of efficacious blood levels.

\section{NSAIDS}

Both cyclooxygenase COX 1 (diclofenac, ibuprofen) and COX 2 (parecoxib) NSAIDS can be used for their analgesic, anti-inflammatory and opioid sparing qualities. The main advantage of the selective COX 2 inhibitors is that they do not affect platelet function significantly to cause bleeding [126]. There are no studies comparing efficacy of different NSAIDS in pancreatic surgery. Due to their gastrointestinal side effects and reduction in renal blood flow, the authors are cautious in recommending their early use in an ERAS pathway for pancreatic surgery until it is clear there is no renal injury. Of note, no data are available for pancreatic surgery regarding the risk of anastomotic leakage in patients with NSAID postoperative treatment.

\section{Intravenous opiates: morphine and hydromorphone}

The use of a morphine or hydromorphone patient-controlled analgesia pump is still widely utilized in pancreatic surgery [127]. In one review of the analgesia used in 8610 patients undergoing PD, only $11 \%$ of patients received epidural analgesia, the rest receiving opioids. Thoracic epidural (TEA) was associated with lower composite postoperative complications [128].The PAKMAN trial, a large RCT, comparing IV analgesia with TEA should add valuable evidence base when completed [129].

\section{Lidocaine infusions}

Lidocaine infusions are being increasingly used intraoperatively to reduce intraoperative and postoperative opioid 
use. There is also an anti-inflammatory effect and improvement in postoperative return of gut function. The optimal dosing and how long to maintain the infusion has not been validated in pancreatic surgery yet [130-133].

\section{Dexmedetomidine}

Dexmedetomidine is a centrally acting alpha- 2 adrenergic agonist. It has multiple effects providing intraoperative analgesia, sedation and postoperative morphine reduction. Its effect on the brain is complex, and it reduces the need for anesthesia [134-136]. It is used as a titrated infusion during surgery only. The main postoperative unwanted side effects are sedation and bradycardia and are dose dependent.

\section{Ketamine}

Ketamine is being used in low-dose infusions in major surgery for its analgesic effect rather than its anesthetic qualities [137, 138]. Higher dosing increases the risk of postoperative cognitive issues, particularly in the elderly.

Summary and recommendations: A postoperative multimodal opioid sparing strategy tailored to each institutional expertise is strongly recommended.

\section{Evidence Level: Moderate}

\section{Recommendation grade: Strong}

13. Wound catheter and transversus abdominis plane (TAP) block

Continuous wound infiltration through a catheter is a reasonable alternative to epidural for open abdominal surgery. A meta-analysis on nine RCTs $(n=505)$ reported no difference in pain control between epidural and wound catheter in abdominal surgery [139]. A second meta-analysis including 29 RCTs $(n=2059)$ reported preperitoneal and subcostal catheters which lead to better pain control than subcutaneous catheters [140]. A recent RCT $(n=105)$ compared continuous wound infiltration to epidural for open hepato-pancreato-biliary surgeries within an enhanced recovery pathway. No significant difference was observed in the composite endpoint of pain scores, opioid side effects and patients' satisfaction. There was a significant reduction in the use of vasopressor in the continuous wound infiltration group, with no difference in postoperative complications or length of stay [141].

Alternative local anesthesia techniques, such as transversus abdominis plane (TAP) blocks, are associated with opioid avoidance, and their use in laparoscopic colorectal surgery within an enhanced recovery is increasingly reported [142]. Currently, no study on the use of TAP blocks for pancreatic surgery within an enhanced recovery setting is available and no recommendation can be drawn for the use of TAP block in PD.

Summary and recommendation: Continuous wound infiltration through preperitoneal catheter is an alternative to epidural for open PD.

Evidence Level: High

Recommendation grade: Strong

14. Postoperative nausea and vomiting (PONV) prophylaxis

Adverse effects of PONV on surgical outcomes include dehydration, electrolyte imbalance, wound dehiscence and delayed discharge [143]. Type of surgery as a risk factor of PONV is debatable, but for patients with three or more other risk factors: female, non-smoking status, history of PONV or motion sickness, and postoperative opioid use, the incidence of PONV ranges from $60 \%$ to $80 \%$, whereas $10 \%$ of patients with no risk factors will experience PONV [143-145].

Scant data that address PONV for patients undergoing PD exist in the literature, but studies related to colorectal, non-cardiac and laparoscopic surgery should be applicable [146]. A comparative study of patients undergoing PD with an ERAS protocol showed that early mobilization, metoclopramide and removal of nasogastric tube on day 1 or day 2 decreased the rate of PONV [147]. A prospective study of 609 patients undergoing elective surgery found that nasogastric tube placement was the most significant factor for PONV based on multiple logistic regression, suggesting that mechanical irritation may increase pharyngeal or vagal nerve stimulation [148].

Several randomized trials have evaluated the therapeutic efficacy of antiemetics in patients undergoing laparoscopic surgery, which is associated with a higher incidence of PONV compared to open surgery [149]. Ramosetron compared to ondansetron was non-inferior for the treatment of PONV in moderate- to high-risk patients undergoing laparoscopic surgery in a randomized, double-blind, multicenter trial [149]. Dexamethasone combined with midazolam significantly lowered the incidence of nausea and vomiting compared with placebo after laparoscopic cholecystectomy [150]. One meta-analysis found that dexamethasone was better than ondansetron for preventing postoperative nausea in the early postoperative period (4-6 h) after laparoscopic surgery, whereas both drugs were equally effective in preventing vomiting until $24 \mathrm{~h}$ [151]. Another meta-analysis found that the 5-hydroxytryptamine type 3 receptor antagonist combined with dexamethasone was significantly more effective than the 
5-HT3 receptor alone in preventing PONV after laparoscopic surgery [152].

A prospective study reported a strong dose-response relationship between postoperative opioid use and PONV [153]. A large retrospective study found that $23 \%$ of patients with fentanyl-based intravenous patient-controlled analgesia after general anesthesia experience PONV despite single drug prophylaxis of 5-hydroxytryptamine type 3 receptor antagonist [154]. Long duration of anesthesia and the intraoperative use of desflurane were identified as independent risk factors. A recent randomized controlled crossover study showed that opioid-induced nausea and vomiting was reduced by headrest rather than eye closure, suggesting an intra-vestibular rather than a visual vestibular mismatch [155].

Summary and recommendation: All patients should receive PONV prophylaxis. Patients with two or more risk factors for PONV (i.e., female, non-smoking status, history of PONV or motion sickness, and postoperative opioid use) should receive a combination of two antiemetics as prophylaxis. Patients with 3-4 risk factors should receive two to three antiemetics.

Evidence level: Moderate

\section{Recommendation grade: Strong}

\section{Avoiding hypothermia}

Episodes of hypothermia, defined as core temperature below $36{ }^{\circ} \mathrm{C}$, may result in serious adverse postoperative complications, such as increased blood loss, cardiac arrhythmia, increased morbidity, increased mortality and wound infections [156-158]. Hypothermia may increase patients' susceptibility to wound infections by causing vasoconstriction and impaired immunity [159]. Although exposure to the cold operating room environment and anesthetic-induced impairment of thermoregulatory control contribute to hypothermia, other prognostic factors include patient age, body mass index, morbidity rate and length of operation [158].

Several randomized trials and meta-analyses have shown that mild hypothermia is associated with adverse outcomes in patients undergoing abdominal and other noncardiac operations [160-165]. A multivariate regression analysis showed that anesthesia time and volume of $\mathrm{CO} 2$ were independent risk factors for perioperative hypothermia in patients undergoing laparoscopic surgery for gastrointestinal cancer [166].

A randomized trial of patients who received forced-air convective warming for at least $30 \mathrm{~min}$ preoperatively showed a significant decrease in the magnitude of hypothermic exposure compared to patients who received warmed blankets on request [167]. Most studies suggest that an average pre-warming time of $30 \mathrm{~min}$ is sufficient to decrease intraoperative hypothermia [168]. Extending systemic warming before and after the operation may provide additional benefit. In patients undergoing major open abdominal surgery, $2 \mathrm{~h}$ of warming before and $2 \mathrm{~h}$ of warming after the procedure was associated with significantly less blood loss and complication rates compared with patients who received routine intraoperative forced-air warming [158].

Circulating-water garments may transfer more heat than forced-air warming systems, but water leakage is a concern [169]. A randomized trial of circulating-water garments compared to circulating-water garments combined with forced-air warming in major upper abdominal surgery showed that the combined method was significantly noninferior to maintaining intraoperative core temperature [170].

Summary and recommendation: Clinically relevant hypothermia starts at $36{ }^{\circ} \mathrm{C}$ with regard to major adverse outcomes. Active warming (forced-air or circulatingwater garment systems) should be initiated before the induction of anesthesia if the patient's oral temperature is below $36{ }^{\circ} \mathrm{C}$. Intraoperatively, active warming and supportive measures should continue to maintain temperature above $36{ }^{\circ} \mathrm{C}$. Postoperatively, patients should be discharged from the post-anesthesia care unit if temperature is above $36{ }^{\circ} \mathrm{C}$.

Evidence level: High

\section{Recommendation grade: Strong}

\section{Postoperative glycemic control}

Several elements of enhanced recovery protocols such as preoperative carbohydrate treatment instead of overnight fasting, continuous epidural anesthesia for postoperative pain, early feeding and mobilization reduce postoperative insulin resistance and thus reduce the risk of hyperglycemia [171, 172]. Early postoperative hyperglycemia (defined as $>140 \mathrm{mg} / \mathrm{dL}$ ) is significantly associated with postoperative complications after PD [173]. Although high glucose variability may not be associated with an increased risk of postoperative complications, patients with high glucose variability and high glucose values early in the postoperative period are at increased risk for complications [173].

A prospective cohort study reported that high preoperative hemoglobin A1c levels were associated with significantly raised glucose levels after surgery [174]. Patients with a high HbA1c level showed almost a threefold increased risk of overall complications compared to patients with normal levels [174]. Although this association does not support a cause-effect relationship, preoperative 
HbA1c levels may help identify patients at higher risk of poor postoperative glycemic control after major abdominal surgery.

In an observational cohort study of patients undergoing gastrointestinal surgery, early peak postoperative glucose levels higher than $250 \mathrm{mg} / \mathrm{dL}$ compared to early peak levels less than $120 \mathrm{mg} / \mathrm{dL}$ were associated with increased 30-day readmissions, whereas preoperative HbA1c levels higher than $6.5 \%$ were associated with fewer postoperative complications and a lower chance of readmission [175]. The authors hypothesized that patients with elevated preoperative HbA1c levels may be more attentively monitored with a lower threshold of hyperglycemia for insulin treatment, adding that elevated early glucose levels may be more suggestive of adverse events following surgery [175].

Perioperative hyperglycemia may increase the risk of surgical site infections in general surgery patients $[176,177]$. In gastroenterological surgery, hyperglycemia was not a significant risk factor for SSI in patients with diabetes, but a blood glucose level of $>150 \mathrm{mg} / \mathrm{dL}$ was associated with an increased odds of SSI in patients without diabetes [177]. A randomized study of patients undergoing hepatic and pancreatic surgery, including PD, found that perioperative intensive insulin therapy with a target blood glucose range of 4.4-6.1 mmol/L decreased rates of SSI compared to a blood glucose range of 7.7-10.0 mmol/ L [178]. The intensive therapy group had a shorter length of hospitalization and a lower incidence of postoperative pancreatic fistula compared to patients in the intermediate insulin therapy group [178].

The optimal blood glucose levels in the early postoperative period associated with improved clinical outcomes for surgical patients remain unclear, as is the non-inferiority of strict glucose control compared to conventional management [179]. Multicenter trials have shown that intensive insulin treatment leads to a higher incidence of hypoglycemia and increased mortality compared to moderate glucose control [180-182]. A randomized study in patients with pancreatogenic diabetes after pancreatic resection who received continuous monitoring of blood glucose levels with an artificial endocrine pancreas showed a significantly higher total insulin dose in the first postoperative $18 \mathrm{~h}$ without hypoglycemia compared with patients who had glucose levels controlled with a sliding scale method [183].

Summary and recommendation: Current data support an association between elevated blood glucose and adverse clinical outcomes in patients with and without diabetes. The optimal glycemic target during the perioperative period remains unclear. Glucose levels should be maintained as close to normal as possible without compromising patient safety. Perioperative treatments that reduce insulin resistance without causing hypoglycemia are recommended. Strong evidence to support the non-inferiority of strict glycemic control (blood glucose levels within normal and narrow range) compared with conventional management is lacking.

\section{Evidence level: Moderate}

Grade of recommendation: Strong

\section{Nasogastric intubation}

Several meta-analyses in patients with gastrectomy or abdominal surgery have shown that the selective nasogastric intubation is associated with a decreased length of hospital stay [184-186], an accelerated oral intake [185, 186] and an earlier recovery of bowel function [184, 185, 187]. Routine nasogastric intubation brings discomfort to the patient and is associated with increased respiratory complications in abdominal and colorectal surgery [187, 188]. Its use as a manner of decreasing anastomotic leakage is not effective in abdominal surgery [184, 185].

Most of the studies on nasogastric intubation in PD are historical series divided into pre- and post-ERAS implementation period. The improvements in length of hospital stay, incidence of DGE, accelerated bowel recovery and reintroduction of diet likely result from a myriad of changes in the perioperative care introduced by ERAS pathways [189, 190].

Historical series that evaluated the use of selective nasogastric intubation have shown no differences in insertion/reinsertion rates of the nasogastric tubes (range 4-19\%), while the use of percutaneous gastrostomy to avoid nasal discomfort actually leads to both increased reoperation $(23.3 \%)$ and morbidity rates [191-196]. In the largest historical series to date $(n=250)$, routine nasogastric intubation was associated with an increased length of hospital stay, with delays in both liquid and solid diet initiation and independently correlated with DGE [195]. Keeping with the previous guidelines, nasogastric tubes placed during the surgery should be removed before the end of the anesthesia.

Summary and recommendation: Maintenance of nasogastric intubation after surgery does not improve outcomes, and their routine use is not warranted

Level of evidence: Moderate

Grade of recommendation: Strong

18. Fluid balance

Numerous observational studies, including more than 1700 patients, reported an increased rate of complications associated with increased intra- and/or perioperative fluid 
administration after PD [197-203]. Excessive perioperative fluid administration causes interstitial fluid shift, and the consequent edema of the bowel wall triggers an inflammatory response with decreased anastomotic stability [203]. This could be deleterious to the pancreato-enterostomy. To date, four observational studies, gathering more than 400 patients, described an increased rate of pancreatic fistula associated with intra- and/or per-operative fluid overload [198, 204-206].

The role of a restrictive fluid protocol for PD was investigated in a recent meta-analysis (five RCTs and two observational studies, $n=846$ ) that found no difference in postoperative outcomes (pancreatic fistula, delayed gastric emptying, complications, length of stay or mortality) associated with a restrictive protocol [207-211]. However, each study had a different definition of restrictive protocol, and some were only applied either in the intra- or in the postoperative period, making the conclusions questionable. Another randomized trial on restrictive fluid management in 330 patients undergoing pancreatic resection found no difference in major perioperative complications between restrictive and liberal fluid management, despite neither goal-directed fluid therapy nor enhanced recovery protocol was used [211]. The latest randomized trial on fluid therapy for PD included patients within an enhanced recovery protocol and compared fluid therapy with or without a cardiac output goal-directed therapy algorithm [212]. A significant reduction in length of stay, intraoperative crystalloids and number of complications was found. The additional value of goal-directed fluid therapy when administered in conjunction with an enhanced recovery protocol is still a matter of debate, as a recent meta-analysis (23 studies, 2099 patients) found no difference in length of stay or morbidity when goal-directed fluid therapy was added within an enhanced recovery protocol for major elective abdominal surgery [213]. Of notice, this metaanalysis included mainly colorectal surgery where insensible blood loss is thought to be lower compared to pancreatic surgery. Further studies on the definition of fluid balance and on the way of achieving fluid overload are needed for pancreatic surgery within an enhanced recovery program.

Summary and recommendation: Avoidance of fluid overload in patients within an enhanced recovery protocol results in improved outcome. A goal-directed fluid therapy algorithm using intra- and postoperative noninvasive monitoring is associated with reduced perioperative fluid administration and potentially improved outcome.
Evidence level: Moderate
Grade of recommendation: Strong

\section{Perianastomotic drainage}

Three RCTs comparing placement of an intra-abdominal drain versus no-drain at the time of surgery after pancreatic cancer resection reveal controversial results. Conlon et al. [214] conducted a RCT of 179 patients reporting a higher incidence of POPF, intra-abdominal abscesses or collections within the drainage group. Accordingly, Witzigmann et al. [215] evaluated 395 patients undergoing PD showing a significant reduction in POPF occurrence and fistula-associated complications in the no-drain group. However, another RCT by Van Buren et al. [216] comprising 137 consecutive PD patients had to be aborted early due to an increase in POPF, DGE and intra-abdominal abscesses and a fourfold increase in mortality in the no-drain group. Subgroup analysis providing risk stratification according to the Fistula Risk Score (FRS) revealed that patients with a negligible/low-risk status had higher rates of clinically relevant POPF when drains were used; conversely, there were significantly fewer POPF when drains were used in moderate-/high-risk patients [217, 218].

Evaluation of early (postoperative day 3) versus late (postoperative day 5 and beyond) drain removal has been examined in an RCT [219]. Early removal of the drain in patients at low risk of POPF (amylase value in drains $<5000 \mathrm{U} / \mathrm{L}$ at postoperative day 3) was associated with a significantly decreased rate of pancreatic fistula, abdominal and pulmonary complications. Therefore, a more selective, individual risk-stratified approach to intraoperative drainage placement might be justified. Several prospective and retrospective NSQUIP database analyses support that amylase activity in the abdominal drainage on postoperative day 1 has a highly predictive value for occurrence of POPF and might be beneficial for decision on early drainage removal [220-222]. A selective drain management protocol could be successfully implemented [223]. By a no-drain management in negligible/low-risk patients (FRS 0-2), a drain-dependent regimen for medium-/high-risk patients (FRS 3-10) with early drain removal on day 3 when low amylase levels occurred $(\leq 5000 \mathrm{U} / \mathrm{L}$ at day 1$)$ or later at surgeons discretion (amylase $>5000$ at day 1), morbidity, incidence of POPF and hospital stay could be significantly reduced [223]. We found no data to support the use of lipase rather than amylase levels for this decision making process.

Due to controversial data for non-drainage regimen in pancreatic surgery, a conservative approach with systematic postoperative drainage and early removal in patients at low risk of POPF might be recommended until data that are more distinct will be available. Finally, no data were found related to postoperative pain control from drains, which might be an issue for faster recovery. 
Summary and recommendation: There is conflicting evidence on a no-drain approach in pancreatic surgery. Early drain removal at $72 \mathrm{~h}$ is advisable in patients with an amylase content in the surgical drain $<5000 \mathrm{U} / \mathrm{L}$ on POD1.

\section{Evidence level:}

- Selective no-drain regimen: Moderate

- Early removal: High.

\section{Grade of recommendation:}

- Selective no-drain regimen: Weak

- Early removal: Strong

\section{Somatostatin analogues}

Our literature search identified 13 RCTs and 12 systematic reviews on the effectiveness of somatostatin analogues to reduce pancreatic fistula complications after pancreatic surgery [224-247]. The latest Cochrane review on the effectiveness of somatostatin analogues was published in 2013 [247]. This systematic review included 21 trials with 2348 patients. There was no significant difference in perioperative mortality in patients who did or did not receive somatostatin analogues. The incidence of pancreatic fistula was lower in the somatostatin analogue group. Most trials did not mention the proportion of these fistulas that were clinically significant, but on inclusion of trials that clearly distinguished clinically significant fistulas, there was no significant difference between the two groups. The authors concluded that somatostatin analogues may reduce perioperative complications but do not reduce perioperative mortality. However, those results should be taken with caution due to the heterogeneity in the quality of studies included in the systematic review. Subgroup analyses for the variability in the texture and duct size of the pancreas are not available in most studies. More recently, the use of pasireotide, a somatostatin analogue that has a longer half-life than octreotide, has been assessed in a single-center, randomized, industry sponsored, doubleblind trial including 300 patients ( 152 patients received 900 micrograms of subcutaneous pasireotide and 148 patients received a placebo twice daily beginning preoperatively on the morning of the operation and continuing for 7 days) [224]. The results of this study showed that the rate of clinically significant pancreatic fistulas (grade 3 or more), leak or abscess was significantly lower in the pasireotide group. Subgroup analysis showed similar results in patients with a non-dilated pancreatic duct.

Summary and recommendation: The systematic use of somatostatin analogues to reduce clinically significant
POPF cannot be recommended because trial results have not been validated yet.

\section{Evidence level: Moderate}

Grade of recommendation: Weak

\section{Urinary drainage}

If thoracic epidural analgesia is used, most patients will have trouble in voiding in the first days postoperatively, and an indwelling urinary catheter will be necessary. The choice between a transurethral or a percutaneous suprapubic drainage will be based on patient comfort, ease of weaning and complications [248]. No trials specifically address this issue for pancreatic surgery patients [248].

Summary and recommendations: In patients with wound catheters or intravenous analgesia, urinary catheters can be removed on the first postoperative day or as soon as the patient is independently ambulant. All other patients should leave the operative room with an indwelling urinary catheter.

Level of evidence: Low

Grade of recommendation: Strong

\section{Delayed gastric emptying (DGE)}

Delayed gastric emptying after PD has an incidence of $15-35 \%$ [33, 249-252]. Since only a subset of patients will develop DGE requiring nasogastric decompression, there is no need for routine insertion of a nasogastric tube after PD. The widely used definition and classification of DGE as described by the International Study Group of Pancreatic Surgery (ISGPS) are based on the duration of the need for an NG tube but does not take into account the etiology [253]. Although primary DGE does occur, DGE is most commonly secondary and related to postoperative complications such as POPF and intra-abdominal infections [251, 254, 255]. Elderly and diabetic patients appear to have a greater risk to develop DGE after PD [255, 256]. Several meta-analyses assessed the relation between DGE and various surgical techniques but found no differences in DGE when looking at reconstruction of the gastro-/duodenojejunostomy in an ante-colic versus retrocolic fashion [257, 258], a pancreaticojejunostomy versus pancreaticogastrostomy $[259,260]$ or a pylorus-preserving resection versus the classical Whipple's procedure [261]. Minimally invasive PD does not reduce the rate of DGE compared with the open approach [262].

DGE is associated with substantially increased hospital costs and health care utilization [33, 263]. It is also worthwhile mentioning that prolonged DGE seems to be related to worse oncological outcomes [264]. In persisting DGE, better outcomes are achieved when artificial 
nutrition, either parenteral or enteral, is started within 10 days of operation [249]. In this context, enteral feeding beyond the gastrojejunostomy is to be preferred over parenteral nutrition [265].

Summary and recommendation: DGE after PD is mainly associated with postoperative complications as POPF and intra-abdominal infections. There are no acknowledged strategies to prevent DGE, although a timely diagnosis and treatment of intra-abdominal complications might reduce the duration of DGE. In patients with prolonged DGE, administration of artificial nutrition can improve outcome.

Evidence level: Low

Grade of recommendation: Strong

\section{Stimulation of bowel movement}

Chewing gum, according to meta-analyses of RCTs, promotes earlier recovery of bowel movements by $16 \mathrm{~h}$ in colorectal surgery and by 0.51 days in abdominal surgery [266, 267]. Common posology is three times a day, for 30-60 min. A RCT on its efficacy in PD showed a trend in the improvement in bowel function and no adverse events related to chewing [268]. Due to the adoption of the ERAS protocol in the middle of the trial, this study had to be terminated early $(n=51)$ and did not reach statistical significance [268]. Overall, chewing gum is a safe intervention and seems to improve bowel function.

Antiadhesive agents have varying effects. Polylactic film was associated with a decrease in ileus in a retrospective cohort study of 179 patients $(4.1 \%$ vs. $13.3 \%)$ at the expense of complications such as skin infections and abdominal fluid collections [269]. A Cochrane meta-analysis that reviewed three RCTs on hyaluronic acid/carboxymethyl cellulose membranes shows that they prevent adhesions, but have no effect on ileus [270]. So far, no antiadhesive has been recommended as a form of prevention of postoperative ileus.

Data from meta-analyses on RCTs on the use of alvimopan, a u-receptor antagonist, show that a dose of 6-12 mg BID significantly improves bowel function in a dose-dependent manner in abdominal surgery [271-273] and lowers hospital costs [274]. At a dose of $6 \mathrm{mg}$, solid food tolerance was accelerated by $10 \mathrm{~h}$, and bowel movements by $17 \mathrm{~h}$, with a decrease of $14 \mathrm{~h}$ in LoS [271]. There are no specific studies with alvimopan in PD, but there is high evidence to support its use in abdominal surgery.

Moreover, two meta-analyses encompass the use of other pharmacological interventions. Bowel recovery was not significantly improved by dihydroergotamine (two trials), metoclopramide and bromopride (four trials), erythromycin (three RCTs), neostigmine (two trials) and ghrelin receptor antagonists (five trials) [273, 275]. Mosapride, a serotonergic receptor agonist, improves ileus, but so far only small trials have tested it in colorectal surgery [276, 277].

\section{Summary and recommendation}

- Chewing gum is safe and may accelerate bowel recovery.

- Level of evidence: Moderate

- Recommendation grade: Weak

- Alvimopan at a dose of 6-12 mg BID accelerates postoperative ileus recovery.

- Level of evidence: Moderate

- Recommendation grade: Weak

- Mosapride appears to improve ileus.

- Level of evidence: Very low

- Recommendation grade: Weak

- Metoclopramide and bromopride have no effect in ileus.

- Level of evidence: Very low

- Recommendation grade: Weak

- Other drugs (ghrelin receptor antagonists, dihydroergotamine and neostigmine, erythromycin) appear to have no effect in postoperative ileus, and their routine used is not justified.

- Level of evidence: Very low (ghrelin receptor antagonists, dihydroergotamine and neostigmine); moderate (erythromycin)

- Recommendation grade: Weak (ghrelin receptor antagonists, dihydroergotamine and neostigmine); strong (erythromycin)

\section{Postoperative artificial nutrition}

Malnutrition is preponderant among patients with pancreatic cancer, and morbidity rates of up to $40 \%$ after major pancreatic surgery including specific complications such as DGE request thorough identification and timely support of patients at nutritional risk [278-280]. Early normal diet according to tolerance is safe and feasible, according to several RCTs and systematic reviews [281-284], even in the presence of DGE or pancreatic fistula [279, 285]. Therefore, an early normal diet as tolerated should be 
encouraged. In patients in whom intake of less than $60 \%$ of their energy requirements for 7-10 days has to be expected, artificial postoperative nutritional support strategies should be considered [44, 286]. However, the route of administration is debated due to inherent morbidity of either support strategy and ambiguous results of the available literature [287-289]. While some studies showed a beneficial effect of early enteral tube feeding notably due to its potential to maintain gastrointestinal integrity [290-294], either combined parenteral nutrition or total parenteral nutrition has been suggested as alternatives when enteral nutrition was not feasible [295-297]. In frail patients undergoing oncological adjuvant protocols and needing long-term supplementation, feeding through tube jejunostomy may be considered [298, 299]. Considering these principles, an individual approach based on patients' nutritional status, disease presentation and expected postoperative course should guide postoperative support strategies if normal diet at will is not sufficient.

Summary and recommendation: Patients should be allowed a normal diet after surgery without restrictions according to tolerance. Artificial nutrition should be considered as an individual approach according to nutritional status assessment. The enteral route should be preferred.

Evidence level: Early diet according to tolerance: moderate.

\section{Grade of recommendation: Strong.}

\section{Early and scheduled mobilization}

It is well known that bed rest is associated with several deleterious effects such as muscle atrophy, thromboembolic disease and insulin resistance, which may delay patient's recovery [300]. However, the available evidence on specific protocol of mobilization is scarce. A recent review compared specific mobilization protocol to control group following abdominal and thoracic surgery. A low number of studies were identified, with low quality and with conflicting results, as only a minority of the included studies reported a significant improvement in postoperative outcome associated with a specific mobilization protocol [301]. A recent randomized controlled trial for colorectal patients within an enhanced recovery protocol found that the allocation of additional specific staff, such as physiotherapists, effectively increased out-of-bed activities but without improving outcome [302]. The daily targets of mobilization following PD varied empirically in different studies from 1 to $4 \mathrm{~h}$ for the first postoperative day and from 2 to $6 \mathrm{~h}$ for the second postoperative day [189, 303, 304].
Summary and recommendation: Early and active mobilization should be encouraged from day 0 . No evidence for specific protocol or daily targets is available for PD.

\section{Evidence level: Low}

Grade of recommendation: Strong

\section{Minimally invasive surgery}

The 2016 International Hepato-Pancreato-Biliary Association state-of-the-art consensus conference concluded that laparoscopic PD (LPD) is still in the investigational phase and that systematic training programs should be implemented [305]. Furthermore, the 2016 European Association for Endoscopic Surgery clinical consensus conference considered LPD feasible and safe when performed by experienced surgeons, however, only in selected cases and in high-volume centers [306]. Although a recent randomized controlled trial and a meta-analysis addressed the role of ERAS in pancreatic surgery, these studies did not differentiate for outcomes in minimally invasive pancreatic surgery [5, 307].

Recently, three randomized controlled trials compared postoperative outcome after LPD versus OPD in a total of 229 patients [308-310]. The first study by Palanivelu et al. [309] found a significantly shorter LoS with a median of 7 versus 13 days and significantly less intraoperative blood loss with a mean of 250 versus $400 \mathrm{ml}$ in the LPD versus OPD, respectively. Duration of surgery was, however, significantly longer in the laparoscopic group. The second study was the monocenter PADULAP RCT from Spain by Poves et al. [308] in 66 patients. This study found a significantly better outcome regarding Clavien grade $\geq 3$ complications for the LPD compared to OPD. LoS and duration of surgery were comparable in this study. Both studies were single-center studies from highly experienced centers. In both studies, sample size were calculated for length of stay as primary outcome and therefore no definitive conclusions can be drawn on the impact of LPD on postoperative complications. The third study was the multicenter LEOPARD-2 RCT from the Netherlands [310]. All patients were treated according to enhanced recovery principles. This study was stopped early after randomization of 99 patients because of safety concerns with LPD and found no difference in time to functional recovery [311].

A study from the US reviewed 865 patients who underwent minimally invasive PD (MIPD) from the Healthcare Cost and Utilization Project National Inpatient Sample data sets (HCUP-NIS) [312]. Eighty-three percent of patients underwent the procedure in a low volume hospital ( $\leq 22$ MIPD procedures per year). After adjusting 
for patient demographics, comorbidities and clinical diagnosis, an increase in hospital procedural volume was significantly associated with a decrease in the odds of a postoperative complication. A volume threshold was identified at 22 cases per year.

Another study from the USA reviewing 4739 patients from the National Cancer Data Base (NCDB) found that patients who underwent LPD in hospitals with the lowest case volume (1-5 total PD/year) had a 3.7 times higher risk of 30-day mortality compared to the hospitals with the highest case volume ( $>25$ total PDs/year) [313]. Only in the highest volume hospitals was LoS significantly shorter (1.3 day shorter) and readmissions lower with LPD compared to OPD [313].

Finally, a retrospective pan-European multicenter propensity score matched study reviewing 1458 patients from 14 centers in seven countries concluded that there was no difference in major morbidity, mortality and hospital stay between LPD, robot-assisted PD and OPD [314]. This study found a significantly higher POPF $\mathrm{B} / \mathrm{C}$ grade in the laparoscopic group, but no increase was seen in the number of radiological drainages or reoperations.

Summary and recommendation: LPD should only be performed in highly experienced, high-volume centers and only within strict protocols. Safety is still a concern. Future studies should address the benefit of LPD in highvolume centers.

Evidence level: Moderate

Grade of recommendation: Strong

\section{Robot-assisted pancreatoduodenectomy (RAPD)}

No studies were found assessing patients undergoing RAPD within an ERAS protocol. A systematic review and meta-analysis found only five non-randomized prospective studies comparing RAPD with open PD [315]. RAPD was associated with less blood loss and lower overall complications, but longer operative duration. No significant differences were found in the rates of pancreatic fistula, DGE and LoS compared to OPD [315].

Summary and recommendation: Currently, there is insufficient evidence to assess RAPD and it cannot be recommended. Prospective studies from high-volume centers are needed.

Evidence level: Low

Grade of recommendation: Weak

\section{Audit}

In the latest Cochrane review, audit and feedback were associated with improved compliance of physician with recommended practice, as well with improved patient outcome [316]. The way feedback is provided is essential, and the likelihood of improved compliance to the desired process was obtained when a supervisor provided feedback on more than one occasion, in both written and verbal forms, with explicit targets and action plan [316]. With the development of electronic support, the use of electronicbased audit and feedback should be encouraged, as a recent meta-analysis observed an increased compliance with the desired process when electronic audit and feedback were used [317]. According to a recent expert consensus on training and implementation for ERAS, audit and data collection were among the three most important elements for a successful and sustainable implementation [318].

Summary and recommendation: Regular audit and feedback based on an electronic database are essential components of ERAS and are associated with improved compliance and outcome.

Evidence level: Moderate

Grade of recommendation: Strong

\section{Conclusions}

This systematic review presents the updated ERAS guidelines for PD. According to the literature search and experts consensus, the highest level of evidence was available for five items: avoiding hypothermia, use of wound catheter as an alternative to EDA, antimicrobial and thromboprophylaxis protocols and preoperative nutritional interventions for patients with severe weight loss. The results of this review confirm the value of ERAS pathways in pancreatic surgery since it reduces postoperative complications, hospital stay and costs. The use of a standard ERAS protocol as described by the present guidelines is essential in order to have a common language worldwide and to conduct multicenter studies. Therefore, a wellestablished and standardized ERAS protocol is paramount for evidence-based management of patients. Compliance with the new proposed protocol should be documented as part of future trials to allow benchmarking.

\section{References}

1. Cerantola Y, Valerio M, Persson B, Jichlinski P, Ljungqvist O, Hubner M et al (2013) Guidelines for perioperative care after radical cystectomy for bladder cancer: enhanced recovery after surgery (ERAS (R)) society recommendations. Clin Nutr 32(6):879-887

2. Muller S, Zalunardo MP, Hubner M, Clavien PA, Demartines N, Grp ZFTS (2009) A fast-track program reduces complications and length of hospital stay after open colonic surgery. Gastroenterology 136(3):842-847 
3. Roulin D, Donadini A, Gander S, Griesser AC, Blanc C, Hubner $M$ et al (2013) Cost-effectiveness of the implementation of an enhanced recovery protocol for colorectal surgery. Br J Surg 100(8):1108-1114

4. Lassen K, Coolsen MME, Slim K, Carli F, de Aguilar-Nascimento JE, Schäfer M et al (2012) Guidelines for perioperative care for pancreaticoduodenectomy: enhanced recovery after surgery $\left(\right.$ ERAS $\left.^{\circledR}\right)$ society recommendations. Clin Nutr 31(6):817-830

5. Ji HB, Zhu WT, Wei Q, Wang XX, Wang HB, Chen QP (2018) Impact of enhanced recovery after surgery programs on pancreatic surgery: a meta-analysis. World $\mathrm{J}$ Gastroenterol 24(15):1666-1678

6. Schulz KF, Altman DG, Moher D, Grp C (2010) CONSORT 2010 statement: updated guidelines for reporting parallel group randomized trials. Ann Intern Med 152(11):726-W293

7. Schunemann HJ, Oxman AD, Brozek J, Glasziou P, Bossuyt P, Chang $S$ et al (2008) GRADE: assessing the quality of evidence for diagnostic recommendations. Ann Intern Med 149(12):JC6-2

8. Melloul E, Hubner M, Scott M, Snowden C, Prentis J, Dejong $\mathrm{CHC}$ et al (2016) Guidelines for perioperative care for liver surgery: enhanced recovery after surgery (ERAS) society recommendations. World J Surg 40(10):2425-2440. https://doi.org/ 10.1007/s00268-016-3700-1

9. Pike I, Piedt S, Davison CM, Russell K, Macpherson AK, Pickett W (2015) Youth injury prevention in Canada: use of the Delphi method to develop recommendations. BMC Public Health 15:1274

10. Haines TP, Hill AM, Hill KD, McPhail S, Oliver D, Brauer S et al (2011) Patient education to prevent falls among older hospital inpatients: a randomized controlled trial. Arch Intern Med 171(6):516-524

11. Edward GM, Naald N, Oort FJ, de Haes HC, Biervliet JD, Hollmann MW et al (2011) Information gain in patients using a multimedia website with tailored information on anaesthesia. $\mathrm{Br}$ J Anaesth 106(3):319-324

12. Stergiopoulou A, Birbas K, Katostaras T, Mantas J (2007) The effect of interactive multimedia on preoperative knowledge and postoperative recovery of patients undergoing laparoscopic cholecystectomy. Methods Inf Med 46(4):406-409

13. Halaszynski TM, Juda R, Silverman DG (2004) Optimizing postoperative outcomes with efficient preoperative assessment and management. Crit Care Med 32(4 Suppl):S76-S86

14. Hounsome J, Lee A, Greenhalgh J, Lewis SR, SchofieldRobinson OJ, Coldwell CH et al (2017) A systematic review of information format and timing before scheduled adult surgery for peri-operative anxiety. Anaesthesia 72(10):1265-1272

15. Carli F, Charlebois P, Stein B, Feldman L, Zavorsky G, Kim DJ et al (2010) Randomized clinical trial of prehabilitation in colorectal surgery. Br J Surg 97(8):1187-1197

16. Barberan-Garcia A, Ubre M, Roca J, Lacy AM, Burgos F, Risco $\mathrm{R}$ et al (2018) Personalised prehabilitation in high-risk patients undergoing elective major abdominal surgery: a randomized blinded controlled trial. Ann Surg 267(1):50-56

17. Saleh MM, Norregaard P, Jorgensen HL, Andersen PK, Matzen P (2002) Preoperative endoscopic stent placement before pancreaticoduodenectomy: a meta-analysis of the effect on morbidity and mortality. Gastrointest Endosc 56(4):529-534

18. Sewnath ME, Birjmohun RS, Rauws EA, Huibregtse K, Obertop H, Gouma DJ (2001) The effect of preoperative biliary drainage on postoperative complications after pancreaticoduodenectomy. J Am Coll Surg 192(6):726-734

19. Wang CC, Kao JH (2010) Preoperative drainage in pancreatic cancer. N Engl J Med 362(14):1343 author reply 5

20. Velanovich V, Kheibek T, Khan M (2009) Relationship of postoperative complications from preoperative biliary stents after pancreaticoduodenectomy. A new cohort analysis and meta-analysis of modern studies. JOP 10(1):24-29

21. Garcea G, Chee W, Ong SL, Maddern GJ (2010) Preoperative biliary drainage for distal obstruction: the case against revisited. Pancreas 39(2):119-126

22. Sun C, Yan G, Li Z, Tzeng CM (2014) A meta-analysis of the effect of preoperative biliary stenting on patients with obstructive jaundice. Medicine (Baltimore) 93(26):e189

23. Chen Y, Ou G, Lian G, Luo H, Huang K, Huang Y (2015) Effect of preoperative biliary drainage on complications following pancreatoduodenectomy: a meta-analysis. Medicine (Baltimore) 94(29):e1199

24. Moole H, Bechtold M, Puli SR (2016) Efficacy of preoperative biliary drainage in malignant obstructive jaundice: a metaanalysis and systematic review. World J Surg Oncol 14(1):182

25. Scheufele F, Schorn S, Demir IE, Sargut M, Tieftrunk E, Calavrezos L et al (2017) Preoperative biliary stenting versus operation first in jaundiced patients due to malignant lesions in the pancreatic head: a meta-analysis of current literature. Surgery 161(4):939-950

26. Lee PJ, Podugu A, Wu D, Lee AC, Stevens T, Windsor JA (2018) Preoperative biliary drainage in resectable pancreatic cancer: a systematic review and network meta-analysis. HPB 20(6):477-486

27. Fang Y, Gurusamy KS, Wang Q, Davidson BR, Lin H, Xie X et al (2012) Pre-operative biliary drainage for obstructive jaundice. Cochrane Database Syst Rev 9:CD005444

28. Qiu YD, Bai JL, Xu FG, Ding YT (2011) Effect of preoperative biliary drainage on malignant obstructive jaundice: a metaanalysis. World J Gastroenterol 17(3):391-396

29. Shaib Y, Rahal MA, Rammal MO, Mailhac A, Tamim H (2017) Preoperative biliary drainage for malignant biliary obstruction: results from a national database. J Hepato-Biliary-Pancreat Sci 24(11):637-642

30. De Pastena M, Marchegiani G, Paiella S, Malleo G, Ciprani D, Gasparini C et al (2018) Impact of preoperative biliary drainage on postoperative outcome after pancreaticoduodenectomy: an analysis of 1500 consecutive cases. Dig Endosc 30(6):777-784

31. van der Gaag NA, Rauws EA, van Eijck CH, Bruno MJ, van der Harst E, Kubben FJ et al (2010) Preoperative biliary drainage for cancer of the head of the pancreas. $N$ Engl $J$ Med 362(2):129-137

32. Lee PJ, Podugu A, Wu D, Lee AC, Stevens T, Windsor JA (2018) Preoperative biliary drainage in resectable pancreatic cancer: a systematic review and network meta-analysis. HPB (Oxford) 20(6):477-486

33. Eisenberg JD, Rosato EL, Lavu H, Yeo CJ, Winter JM (2015) Delayed gastric emptying after pancreaticoduodenectomy: an analysis of risk factors and cost. J Gastrointest Surg 19(9):1572-1580

34. Aoki S, Miyata H, Konno H, Gotoh M, Motoi F, Kumamaru H et al (2017) Risk factors of serious postoperative complications after pancreaticoduodenectomy and risk calculators for predicting postoperative complications: a nationwide study of 17,564 patients in Japan. J Hepato-Biliary-Pancreat Sci 24(5):243-251

35. Lindstrom D, Sadr Azodi O, Wladis A, Tonnesen H, Linder S, Nasell $\mathrm{H}$ et al (2008) Effects of a perioperative smoking cessation intervention on postoperative complications: a randomized trial. Ann Surg 248(5):739-745

36. Moller AM, Villebro N, Pedersen T, Tonnesen H (2002) Effect of preoperative smoking intervention on postoperative complications: a randomised clinical trial. Lancet 359(9301):114-117

37. Sorensen LT, Jorgensen T (2003) Short-term pre-operative smoking cessation intervention does not affect postoperative 
complications in colorectal surgery: a randomized clinical trial. Colorectal Dis 5(4):347-352

38. Eliasen M, Gronkjaer M, Skov-Ettrup LS, Mikkelsen SS, Becker U, Tolstrup JS et al (2013) Preoperative alcohol consumption and postoperative complications: a systematic review and metaanalysis. Ann Surg 258(6):930-942

39. Hu BY, Wan T, Zhang WZ, Dong JH (2016) Risk factors for postoperative pancreatic fistula: analysis of 539 successive cases of pancreaticoduodenectomy. World J Gastroenterol 22(34):7797-7805

40. Oppedal K, Moller AM, Pedersen B, Tonnesen H (2012) Preoperative alcohol cessation prior to elective surgery. Cochrane Database Syst Rev 7:CD008343

41. Aahlin EK, Trano G, Johns N, Horn A, Soreide JA, Fearon KC et al (2015) Risk factors, complications and survival after upper abdominal surgery: a prospective cohort study. BMC Surg 15:83

42. Olson SH, Xu Y, Herzog K, Saldia A, DeFilippis EM, Li P et al (2016) Weight loss, diabetes, fatigue, and depression preceding pancreatic cancer. Pancreas 45(7):986-991

43. Weimann A, Braga M, Harsanyi L, Laviano A, Ljungqvist O, Soeters $\mathrm{P}$ et al (2006) ESPEN guidelines on enteral nutrition: surgery including organ transplantation. Clin Nutr 25(2):224-244

44. Weimann A, Braga M, Carli F, Higashiguchi T, Hubner M, Klek $S$ et al (2017) ESPEN guideline: clinical nutrition in surgery. Clin Nutr 36(3):623-650

45. Lassen K, Hvarphiye A, Myrmel T (2012) Randomised trials in surgery: the burden of evidence. Rev Recent Clin Trials 7(3):244-248

46. Probst P, Haller S, Bruckner T, Ulrich A, Strobel O, Hackert T et al (2017) Prospective trial to evaluate the prognostic value of different nutritional assessment scores in pancreatic surgery (NURIMAS Pancreas). Br J Surg 104(8):1053-1062

47. Gianotti L, Besselink MG, Sandini M, Hackert T, Conlon K, Gerritsen A et al (2018) Nutritional support and therapy in pancreatic surgery: a position paper of the International Study Group on Pancreatic Surgery (ISGPS). Surgery 164(5):1035-1048

48. Poch B, Lotspeich E, Ramadani M, Gansauge S, Beger HG, Gansauge F (2007) Systemic immune dysfunction in pancreatic cancer patients. Langenbecks Arch Surg 392(3):353-358

49. Ashida R, Okamura Y, Wakabayashi-Nakao K, Mizuno T, Aoki S, Uesaka K (2018) The impact of preoperative enteral nutrition enriched with eicosapentaenoic acid on postoperative hypercytokinemia after pancreatoduodenectomy: the results of a doubleblinded randomized controlled trial. Dig Surg 36:1-9

50. Senkal M, Haaker R, Linseisen J, Wolfram G, Homann HH, Stehle P (2005) Preoperative oral supplementation with longchain $\Omega-3$ fatty acids beneficially alters phospholipid fatty acid patterns in liver, gut mucosa, and tumor tissue. J Parenter Enter Nutr 29(4):236-240

51. Mazaki T, Ishii Y, Murai I (2015) Immunoenhancing enteral and parenteral nutrition for gastrointestinal surgery: a multipletreatments meta-analysis. Ann Surg 261(4):662-669

52. Drover JW, Dhaliwal R, Weitzel L, Wischmeyer PE, Ochoa JB, Heyland DK (2011) Perioperative use of arginine-supplemented diets: a systematic review of the evidence. J Am Coll Surg 212(3):385-399

53. Osland E, Hossain MB, Khan S, Memon MA (2014) Effect of timing of pharmaconutrition (immunonutrition) administration on outcomes of elective surgery for gastrointestinal malignancies: a systematic review and meta-analysis. JPEN J Parenter Enter Nutr 38(1):53-69

54. Cheng Y, Zhang J, Zhang L, Wu J, Zhan Z (2018) Enteral immunonutrition versus enteral nutrition for gastric cancer patients undergoing a total gastrectomy: a systematic review and meta-analysis. BMC Gastroenterol 18(1):11

55. Song GM, Liu XL, Bian W, Wu J, Deng YH, Zhang $H$ et al (2017) Systematic review with network meta-analysis: comparative efficacy of different enteral immunonutrition formulas in patients underwent gastrectomy. Oncotarget 8(14):23376-23388

56. Song GM, Tian X, Zhang L, Ou YX, Yi LJ, Shuai T et al (2015) Immunonutrition support for patients undergoing surgery for gastrointestinal malignancy: preoperative, postoperative, or perioperative? A Bayesian network meta-analysis of randomized controlled trials. Medicine (Baltimore) 94(29):e1225

57. Klek S, Kulig J, Sierzega M, Szybinski P, Szczepanek K, Kubisz A et al (2008) The impact of immunostimulating nutrition on infectious complications after upper gastrointestinal surgery: a prospective, randomized, clinical trial. Ann Surg 248(2):212-220

58. Marano L, Porfidia R, Pezzella M, Grassia M, Petrillo M, Esposito G et al (2013) Clinical and immunological impact of early postoperative enteral immunonutrition after total gastrectomy in gastric cancer patients: a prospective randomized study. Ann Surg Oncol 20(12):3912-3918

59. Ward-Boahen D, Wallace-Kazer M (2014) Improving surgical outcomes in pancreatic surgery with preoperative nutrition. J Adv Pract Oncol 5(2):100-106

60. Hamza N, Darwish A, O'Reilly DA, Denton J, Sheen AJ, Chang D et al (2015) Perioperative enteral immunonutrition modulates systemic and mucosal immunity and the inflammatory response in patients with periampullary cancer scheduled for pancreaticoduodenectomy: a randomized clinical trial. Pancreas 44(1):41-52

61. Aida T, Furukawa K, Suzuki D, Shimizu H, Yoshidome H, Ohtsuka M et al (2014) Preoperative immunonutrition decreases postoperative complications by modulating prostaglandin E2 production and T-cell differentiation in patients undergoing pancreatoduodenectomy. Surgery 155(1):124-133

62. Suzuki D, Furukawa K, Aida T, Uno H, Miyauchi Y, Shimizu H et al (2014) Effects of immunonutrition on postoperative complication, stress responses, and cell-mediated immunity after pancreaticoduodenectomy: results from two randomized controlled studies. Clin Nutr 33:S137-S138

63. Probst P, Ohmann S, Klaiber U, Huttner FJ, Billeter AT, Ulrich A et al (2017) Meta-analysis of immunonutrition in major abdominal surgery. Br J Surg 104(12):1594-1608

64. Ljungqvist $\mathrm{O}(2005)$ To fast or not to fast before surgical stress. Nutrition 21(7-8):885-886

65. Soop M, Nygren J, Myrenfors P, Thorell A, Ljungqvist O (2001) Preoperative oral carbohydrate treatment attenuates immediate postoperative insulin resistance. Am J Physiol Endocrinol Metab 280(4):E576-E583

66. Smith MD, McCall J, Plank L, Herbison GP, Soop M, Nygren J (2014) Preoperative carbohydrate treatment for enhancing recovery after elective surgery. Cochrane Database Syst Rev 8:CD009161

67. Wilson CJ, Mitchelson AJ, Tzeng TH, El-Othmani MM, Saleh J, Vasdev $S$ et al (2016) Caring for the surgically anxious patient: a review of the interventions and a guide to optimizing surgical outcomes. Am J Surg 212(1):151-159

68. Walker KJ, Smith AF (2009) Premedication for anxiety in adult day surgery. Cochrane Database Syst Rev 4:CD002192

69. Hurley RW, Cohen SP, Williams KA, Rowlingson AJ, Wu CL (2006) The analgesic effects of perioperative gabapentin on postoperative pain: a meta-analysis. Reg Anesth Pain Med 31(3):237-247 
70. Mishriky BM, Waldron NH, Habib AS (2015) Impact of pregabalin on acute and persistent postoperative pain: a systematic review and meta-analysis. Br J Anaesth 114(1):10-31

71. Agnelli G, Bolis G, Capussotti L, Scarpa RM, Tonelli F, Bonizzoni E et al (2006) A clinical outcome-based prospective study on venous thromboembolism after cancer surgery: the @RISTOS project. Ann Surg 243(1):89-95

72. Lyman GH (2011) Venous thromboembolism in the patient with cancer: focus on burden of disease and benefits of thromboprophylaxis. Cancer 117(7):1334-1349

73. Lyman GH, Khorana AA, Kuderer NM, Lee AY, Arcelus JI, Balaban EP et al (2013) Venous thromboembolism prophylaxis and treatment in patients with cancer: american Society of Clinical Oncology clinical practice guideline update. J Clin Oncol 31(17):2189-2204

74. Koch A, Bouges S, Ziegler S, Dinkel H, Daures JP, Victor N (1997) Low molecular weight heparin and unfractionated heparin in thrombosis prophylaxis after major surgical intervention: update of previous meta-analyses. Br J Surg 84(6):750-759

75. Kakkos SK, Caprini JA, Geroulakos G, Nicolaides AN, Stansby GP, Reddy DJ (2008) Combined intermittent pneumatic leg compression and pharmacological prophylaxis for prevention of venous thromboembolism in high-risk patients. Cochrane Database Syst Rev 4:CD005258

76. Hayashi H, Morikawa T, Yoshida H, Motoi F, Okada T, Nakagawa K et al (2014) Safety of postoperative thromboprophylaxis after major hepatobiliary-pancreatic surgery in Japanese patients. Surg Today 44(9):1660-1668

77. Tzeng CW, Katz MH, Lee JE, Fleming JB, Pisters PW, Vauthey $\mathrm{JN}$ et al (2014) Predicting the risks of venous thromboembolism versus post-pancreatectomy haemorrhage: analysis of 13,771 NSQIP patients. HPB 16(4):373-383

78. Horlocker TT, Vandermeuelen E, Kopp SL, Gogarten W, Leffert LR, Benzon HT (2018) Regional anesthesia in the patient receiving antithrombotic or thrombolytic therapy: american society of regional anesthesia and pain medicine evidence-based guidelines (fourth edition). Reg Anesth Pain Med 43(3):263-309

79. Kent TS, Sachs TE, Callery MP, Vollmer CM Jr (2013) The burden of infection for elective pancreatic resections. Surgery 153(1):86-94

80. Winter JM, Cameron JL, Campbell KA, Arnold MA, Chang DC, Coleman J et al (2006) 1423 pancreaticoduodenectomies for pancreatic cancer: a single-institution experience. J Gastrointest Surg 10(9):1199-1210 discussion 210-1

81. Fernandez-del Castillo C, Morales-Oyarvide V, McGrath D, Wargo JA, Ferrone CR, Thayer SP et al (2012) Evolution of the Whipple procedure at the Massachusetts General Hospital. Surgery 152(3 Suppl 1):S56-S63

82. Nanashima A, Abo T, Arai J, Oyama S, Mochinaga K, Matsumoto $\mathrm{H}$ et al (2014) Clinicopathological parameters associated with surgical site infections in patients who underwent pancreatic resection. Hepatogastroenterology 61(134):1739-1743

83. Kirkland KB, Briggs JP, Trivette SL, Wilkinson WE, Sexton DJ (1999) The impact of surgical-site infections in the 1990s: attributable mortality, excess length of hospitalization, and extra costs. Infect Control Hosp Epidemiol 20(11):725-730

84. Valle JW, Palmer D, Jackson R, Cox T, Neoptolemos JP, Ghaneh $P$ et al (2014) Optimal duration and timing of adjuvant chemotherapy after definitive surgery for ductal adenocarcinoma of the pancreas: ongoing lessons from the ESPAC-3 study. J Clin Oncol 32(6):504-512

85. Merkow RP, Bilimoria KY, Tomlinson JS, Paruch JL, Fleming JB, Talamonti MS et al (2014) Postoperative complications reduce adjuvant chemotherapy use in resectable pancreatic cancer. Ann Surg 260(2):372-377
86. Bratzler DW, Dellinger EP, Olsen KM, Perl TM, Auwaerter PG, Bolon MK et al (2013) Clinical practice guidelines for antimicrobial prophylaxis in surgery. Am J Health Syst Pharm 70(3):195-283

87. Leaper DJ, Edmiston CE Jr, Holy CE (2017) Meta-analysis of the potential economic impact following introduction of absorbable antimicrobial sutures. Br J Surg 104(2):e134-e144

88. Fujita S, Saito N, Yamada T, Takii Y, Kondo K, Ohue M et al (2007) Randomized, multicenter trial of antibiotic prophylaxis in elective colorectal surgery: single dose vs 3 doses of a second-generation cephalosporin without metronidazole and oral antibiotics. Arch Surg 142(7):657-661

89. Barreto SG, Singh MK, Sharma S, Chaudhary A (2015) Determinants of surgical site infections following pancreatoduodenectomy. World J Surg 39(10):2557-2563. https://doi.org/10. 1007/s00268-015-3115-4

90. Gavazzi F, Ridolfi C, Capretti G, Angiolini MR, Morelli P, Casari E et al (2016) Role of preoperative biliary stents, bile contamination and antibiotic prophylaxis in surgical site infections after pancreaticoduodenectomy. BMC Gastroenterol 16:43

91. Sudo T, Murakami Y, Uemura K, Hashimoto Y, Kondo N, Nakagawa $\mathrm{N}$ et al (2014) Perioperative antibiotics covering bile contamination prevent abdominal infectious complications after pancreatoduodenectomy in patients with preoperative biliary drainage. World J Surg 38(11):2952-2959. https://doi.org/10. 1007/s00268-014-2688-7

92. Fong ZV, McMillan MT, Marchegiani G, Sahora K, Malleo G, De Pastena $M$ et al (2016) Discordance between perioperative antibiotic prophylaxis and wound infection cultures in patients undergoing pancreaticoduodenectomy. JAMA Surg 151(5):432-439

93. van der Gaag NA, Rauws EA, van Eijck CH, Bruno MJ, van der Harst E, Kubben FJ et al (2010) Preoperative biliary drainage for pancreatic head tumours: more complications. Ned Tijdschr Geneeskd 154(29):A1883

94. Sudo T, Murakami Y, Uemura K, Hayashidani Y, Hashimoto Y, Ohge $\mathrm{H}$ et al (2007) Specific antibiotic prophylaxis based on bile cultures is required to prevent postoperative infectious complications in pancreatoduodenectomy patients who have undergone preoperative biliary drainage. World J Surg 31(11):2230-2235. https://doi.org/10.1007/s00268-007-9210-4

95. Okamura K, Tanaka K, Miura T, Nakanishi Y, Noji T, Nakamura $\mathrm{T}$ et al (2017) Randomized controlled trial of perioperative antimicrobial therapy based on the results of preoperative bile cultures in patients undergoing biliary reconstruction. J HepatoBiliary-Pancreat Sci 24(7):382-393

96. Kondo K, Chijiiwa K, Ohuchida J, Kai M, Fujii Y, Otani K et al (2013) Selection of prophylactic antibiotics according to the microorganisms isolated from surgical site infections (SSIs) in a previous series of surgeries reduces SSI incidence after pancreaticoduodenectomy. J Hepato-Biliary-Pancreat Sci 20(3):286-293

97. Fathi AH, Jackson T, Barati M, Eghbalieh B, Siegel KA, Siegel CT (2016) Extended perioperative antibiotic coverage in conjunction with intraoperative bile cultures decreases infectious complications after pancreaticoduodenectomy. HPB Surg 2016:3031749

98. Sourrouille I, Gaujoux S, Lacave G, Bert F, Dokmak S, Belghiti $\mathrm{J}$ et al (2013) Five days of postoperative antimicrobial therapy decreases infectious complications following pancreaticoduodenectomy in patients at risk for bile contamination. HPB 15(6):473-480

99. Donald GW, Sunjaya D, Lu X, Chen F, Clerkin B, Eibl G et al (2013) Perioperative antibiotics for surgical site infection in pancreaticoduodenectomy: does the SCIP-approved regimen provide adequate coverage? Surgery 154(2):190-196 
100. Tanaka K, Nakamura T, Imai S, Kushiya H, Miyasaka D, Nakanishi Y et al (2018) The use of broad-spectrum antibiotics reduces the incidence of surgical site infection after pancreatoduodenectomy. Surg Today 23:23

101. Mohammed S, Evans C, VanBuren G, Hodges SE, Silberfein E, Artinyan A et al (2014) Treatment of bacteriobilia decreases wound infection rates after pancreaticoduodenectomy. HPB 16(6):592-598

102. Ban KA, Minei JP, Laronga C, Harbrecht BG, Jensen EH, Fry DE et al (2017) American College of Surgeons and Surgical Infection Society: surgical site infection guidelines, 2016 update. J Am Coll Surg 224(1):59-74

103. Giske A, Nymo LS, Fuskevag OM, Amundsen S, Simonsen GS, Lassen K (2017) Systemic antibiotic prophylaxis prior to gastrointestinal surgery-is oral administration of doxycycline and metronidazole adequate? Infect Dis (Lond) 49(11-12):785-791

104. Sidhwa F, Itani KM (2015) Skin preparation before surgery: options and evidence. Surg Infect (Larchmt) 16(1):14-23

105. Maiwald M, Chan ES (2012) The forgotten role of alcohol: a systematic review and meta-analysis of the clinical efficacy and perceived role of chlorhexidine in skin antisepsis. PLOS ONE 7(9):e44277

106. Dumville JC, McFarlane E, Edwards P, Lipp A, Holmes A, Liu Z (2015) Preoperative skin antiseptics for preventing surgical wound infections after clean surgery. Cochrane Database Syst Rev 4:CD003949

107. Park HM, Han SS, Lee EC, Lee SD, Yoon HM, Eom BW et al (2017) Randomized clinical trial of preoperative skin antisepsis with chlorhexidine gluconate or povidone-iodine. Br J Surg 104(2):e145-e150

108. Webster J, Alghamdi A (2015) Use of plastic adhesive drapes during surgery for preventing surgical site infection. Cochrane Database Syst Rev 4:3

109. Cheng KP, Roslani AC, Sehha N, Kueh JH, Law CW, Chong HY et al (2012) ALEXIS O-Ring wound retractor vs conventional wound protection for the prevention of surgical site infections in colorectal resections(1). Colorectal Dis 14(6): $346-\mathrm{e} 351$

110. Reid K, Pockney P, Draganic B, Smith SR (2010) Barrier wound protection decreases surgical site infection in open elective colorectal surgery: a randomized clinical trial. Dis Colon Rectum 53(10):1374-1380

111. Kang SI, Oh HK, Kim MH, Kim MJ, Kim DW, Kim HJ et al (2018) Systematic review and meta-analysis of randomized controlled trials of the clinical effectiveness of impervious plastic wound protectors in reducing surgical site infections in patients undergoing abdominal surgery. Surgery 164(5):939-945

112. Allegranzi B, Zayed B, Bischoff P, Kubilay NZ, de Jonge S, de Vries F et al (2016) New WHO recommendations on intraoperative and postoperative measures for surgical site infection prevention: an evidence-based global perspective. Lancet Infect Dis 16(12): e288-e303

113. Bruns H, Rahbari NN, Loffler T, Diener MK, Seiler CM, Glanemann $\mathrm{M}$ et al (2009) Perioperative management in distal pancreatectomy: results of a survey in 23 European participating centres of the DISPACT trial and a review of literature. Trials 10:58

114. Block BM, Liu SS, Rowlingson AJ, Cowan AR, Cowan JA Jr, Wu CL (2003) Efficacy of postoperative epidural analgesia: a meta-analysis. JAMA 290(18):2455-2463

115. Werawatganon T, Charuluxananan S (2013) WITHDRAWN: patient controlled intravenous opioid analgesia versus continuous epidural analgesia for pain after intra-abdominal surgery. Cochrane Database Syst Rev 3:CD004088
116. Salicath JH, Yeoh EC, Bennett MH (2018) Epidural analgesia versus patient-controlled intravenous analgesia for pain following intra-abdominal surgery in adults. Cochrane Database Syst Rev 8:CD010434

117. Guay J, Nishimori M, Kopp S (2016) Epidural local anaesthetics versus opioid-based analgesic regimens for postoperative gastrointestinal paralysis, vomiting and pain after abdominal surgery. Cochrane Database Syst Rev 7:CD001893

118. Popping DM, Elia N, Marret E, Remy C, Tramer MR (2008) Protective effects of epidural analgesia on pulmonary complications after abdominal and thoracic surgery: a meta-analysis. Arch Surg 143(10):990-999 discussion 1000

119. Schricker T, Lattermann R (2007) Strategies to attenuate the catabolic response to surgery and improve perioperative outcomes. Can J Anaesth 54(6):414-419

120. Carli F, Halliday D (1997) Continuous epidural blockade arrests the postoperative decrease in muscle protein fractional synthetic rate in surgical patients. Anesthesiology 86(5):1033-1040

121. Soop M, Carlson GL, Hopkinson J, Clarke S, Thorell A, Nygren $\mathrm{J}$ et al (2004) Randomized clinical trial of the effects of immediate enteral nutrition on metabolic responses to major colorectal surgery in an enhanced recovery protocol. Br J Surg 91(9):1138-1145

122. Pratt WB, Steinbrook RA, Maithel SK, Vanounou T, Callery MP, Vollmer CM Jr (2008) Epidural analgesia for pancreatoduodenectomy: a critical appraisal. J Gastrointest Surg 12(7):1207-1220

123. Cook TM, Counsell D, Wildsmith JA, Royal College of Anaesthetists Third National Audit P (2009) Major complications of central neuraxial block: report on the Third National Audit Project of the Royal College of Anaesthetists. Br J Anaesth 102(2):179-190

124. Day AR, Smith RV, Scott MJ, Fawcett WJ, Rockall TA (2015) Randomized clinical trial investigating the stress response from two different methods of analgesia after laparoscopic colorectal surgery. Br J Surg 102(12):1473-1479

125. McNicol ED, Ferguson MC, Haroutounian S, Carr DB, Schumann R (2016) Single dose intravenous paracetamol or intravenous propacetamol for postoperative pain. Cochrane Database Syst Rev 5:CD007126

126. Teerawattananon C, Tantayakom P, Suwanawiboon B, Katchamart W (2017) Risk of perioperative bleeding related to highly selective cyclooxygenase-2 inhibitors: a systematic review and meta-analysis. Semin Arthritis Rheum 46(4):520-528

127. Brummett CM, Waljee JF, Goesling J, Moser S, Lin P, Englesbe MJ et al (2017) New persistent opioid use after minor and major surgical procedures in US adults. JAMA Surg 152(6):e170504

128. Amini A, Patanwala AE, Maegawa FB, Skrepnek GH, Jie T, Gruessner RW et al (2012) Effect of epidural analgesia on postoperative complications following pancreaticoduodenectomy. Am J Surg 204(6): 1000-1004 discussion 4-6

129. Klotz R, Hofer S, Schellhaass A, Dorr-Harim C, Tenckhoff S, Bruckner $T$ et al (2016) Intravenous versus epidural analgesia to reduce the incidence of gastrointestinal complications after elective pancreatoduodenectomy (the PAKMAN trial, DRKS 00007784): study protocol for a randomized controlled trial. Trials 17:194

130. Weibel S, Jelting Y, Pace NL, Helf A, Eberhart LH, Hahnenkamp $\mathrm{K}$ et al (2018) Continuous intravenous perioperative lidocaine infusion for postoperative pain and recovery in adults. Cochrane Database Syst Rev 6:CD009642

131. Dunn LK, Durieux ME (2017) Perioperative use of intravenous lidocaine. Anesthesiology 126(4):729-737

132. Khan JS, Yousuf M, Victor JC, Sharma A, Siddiqui N (2016) An estimation for an appropriate end time for an intraoperative 
intravenous lidocaine infusion in bowel surgery: a comparative meta-analysis. J Clin Anesth 28:95-104

133. Kranke P, Jokinen J, Pace NL, Schnabel A, Hollmann MW, Hahnenkamp K et al (2015) Continuous intravenous perioperative lidocaine infusion for postoperative pain and recovery. Cochrane Database Syst Rev 7:CD009642

134. Fragen RJ, Fitzgerald PC (1999) Effect of dexmedetomidine on the minimum alveolar concentration (MAC) of sevoflurane in adults age 55 to 70 years. J Clin Anesth 11(6):466-470

135. Le Bot A, Michelet D, Hilly J, Maesani M, Dilly MP, Brasher C et al (2015) Efficacy of intraoperative dexmedetomidine compared with placebo for surgery in adults: a meta-analysis of published studies. Minerva Anestesiol 81(10):1105-1117

136. Bellon M, Le Bot A, Michelet D, Hilly J, Maesani M, Brasher C et al (2016) Efficacy of intraoperative dexmedetomidine compared with placebo for postoperative pain management: a metaanalysis of published studies. Pain Ther 5(1):63-80

137. Elia N, Tramer MR (2005) Ketamine and postoperative pain-a quantitative systematic review of randomised trials. Pain 113(1-2):61-70

138. Laskowski K, Stirling A, McKay WP, Lim HJ (2011) A systematic review of intravenous ketamine for postoperative analgesia. Can J Anaesth 58(10):911-923

139. Ventham NT, Hughes M, O’Neill S, Johns N, Brady RR, Wigmore SJ (2013) Systematic review and meta-analysis of continuous local anaesthetic wound infiltration versus epidural analgesia for postoperative pain following abdominal surgery. Br J Surg 100(10):1280-1289

140. Mungroop TH, Bond MJ, Lirk P, Busch OR, Hollmann MW, Veelo DP et al (2019) Preperitoneal or subcutaneous wound catheters as alternative for epidural analgesia in abdominal surgery: a systematic review and meta-analysis. Ann Surg 269(2):252-260

141. Mungroop TH, Veelo DP, Busch OR, van Dieren S, van Gulik TM, Karsten TM et al (2016) Continuous wound infiltration versus epidural analgesia after hepato-pancreato-biliary surgery (POP-UP): a randomised controlled, open-label, non-inferiority trial. Lancet Gastroenterol Hepatol 1(2):105-113

142. Siddiqui MR, Sajid MS, Uncles DR, Cheek L, Baig MK (2011) A meta-analysis on the clinical effectiveness of transversus abdominis plane block. J Clin Anesth 23(1):7-14

143. Roberts SM, Bezinover DS, Janicki PK (2012) Reappraisal of the role of dolasetron in prevention and treatment of nausea and vomiting associated with surgery or chemotherapy. Cancer Manag Res 4:67-73

144. Gan TJ, Diemunsch P, Habib AS, Kovac A, Kranke P, Meyer TA et al (2014) Consensus guidelines for the management of postoperative nausea and vomiting. Anesth Analg 118(1):85-113

145. Apfel CC, Heidrich FM, Jukar-Rao S, Jalota L, Hornuss C, Whelan RP et al (2012) Evidence-based analysis of risk factors for postoperative nausea and vomiting. $\mathrm{Br} \mathrm{J}$ Anaesth 109(5):742-753

146. Carmichael JC, Keller DS, Baldini G, Bordeianou L, Weiss E, Lee L et al (2017) Clinical practice guidelines for enhanced recovery after colon and rectal surgery from the American Society of Colon and Rectal Surgeons and Society of American Gastrointestinal and Endoscopic Surgeons. Dis Colon Rectum 60(8):761-784

147. Balzano G, Zerbi A, Braga M, Rocchetti S, Beneduce AA, Di Carlo V (2008) Fast-track recovery programme after pancreaticoduodenectomy reduces delayed gastric emptying. Br J Surg 95(11): 1387-1393

148. Son J, Yoon H (2018) Factors affecting postoperative nausea and vomiting in surgical patients. $J$ Perianesth Nurs 33(4):461-470
149. Choi YS, Sohn HM, Do SH, Min KT, Woo JH, Baik HJ (2018) Comparison of ramosetron and ondansetron for the treatment of established postoperative nausea and vomiting after laparoscopic surgery: a prospective, randomized, double-blinded multicenter trial. Ther Clin Risk Manag 14:601-606

150. Gupta R, Srivastava S, Dhiraaj S, Chovatiya PP (2018) Minimum effective dose of dexamethasone in combination with midazolam as prophylaxis against postoperative nausea and vomiting after laparoscopic cholecystectomy. Anesth Essays Res 12(2):396-401

151. Maitra S, Som A, Baidya DK, Bhattacharjee S (2016) Comparison of ondansetron and dexamethasone for prophylaxis of postoperative nausea and vomiting in patients undergoing laparoscopic surgeries: a meta-analysis of randomized controlled trials. Anesthesiol Res Pract 2016:7089454

152. Som A, Bhattacharjee S, Maitra S, Arora MK, Baidya DK (2016) Combination of 5-HT3 antagonist and dexamethasone is superior to 5-HT3 antagonist alone for PONV prophylaxis after laparoscopic surgeries: a meta-analysis. Anesth Analg 123(6): 1418-1426

153. Roberts GW, Bekker TB, Carlsen HH, Moffatt CH, Slattery PJ, McClure AF (2005) Postoperative nausea and vomiting are strongly influenced by postoperative opioid use in a dose-related manner. Anesth Analg 101(5):1343-1348

154. Choi JB, Shim YH, Lee YW, Lee JS, Choi JR, Chang CH (2014) Incidence and risk factors of postoperative nausea and vomiting in patients with fentanyl-based intravenous patient-controlled analgesia and single antiemetic prophylaxis. Yonsei Med J 55(5):1430-1435

155. Heuser F, Schulz C, Saglam M, Ramaioli C, Heuberger M, Wagner KJ et al (2017) Preventing opioid-induced nausea and vomiting: rest your head and close your eyes? PLoS ONE 12(3): 0173925

156. De Pietri L, Montalti R, Begliomini B (2014) Anaesthetic perioperative management of patients with pancreatic cancer. World J Gastroenterol 20(9):2304-2320

157. Torossian A (2008) Thermal management during anaesthesia and thermoregulation standards for the prevention of inadvertent perioperative hypothermia. Best Pract Res Clin Anaesthesiol 22(4):659-668

158. Wong PF, Kumar S, Bohra A, Whetter D, Leaper DJ (2007) Randomized clinical trial of perioperative systemic warming in major elective abdominal surgery. Br J Surg 94(4):421-426

159. Kurz A, Sessler DI, Lenhardt R (1996) Perioperative normothermia to reduce the incidence of surgical-wound infection and shorten hospitalization. Study of wound infection and temperature group. N Engl J Med 334(19):1209-1215

160. Frank SM, Fleisher LA, Breslow MJ, Higgins MS, Olson KF, Kelly S et al (1997) Perioperative maintenance of normothermia reduces the incidence of morbid cardiac events. A randomized clinical trial. JAMA 277(14):1127-1134

161. Hasegawa K, Negishi C, Nakagawa F, Ozaki M (2012) Core temperatures during major abdominal surgery in patients warmed with new circulating-water garment, forced-air warming, or carbon-fiber resistive-heating system. J Anesth 26(2):168-173

162. Zhao J, Luo AL, Xu L, Huang YG (2005) Forced-air warming and fluid warming minimize core hypothermia during abdominal surgery. Chin Med Sci J 20(4):261-264

163. Zeba S, Surbatovic M, Marjanovic M, Jevdjic J, Hajdukovic Z, Karkalic R et al (2016) Efficacy of external warming in attenuation of hypothermia in surgical patients. Vojnosanit Pregl 73(6):566-571

164. Scott EM, Buckland R (2006) A systematic review of intraoperative warming to prevent postoperative complications. AORN J 83(5):1090-104, 107-13 
165. Rajagopalan S, Mascha E, Na J, Sessler DI (2008) The effects of mild perioperative hypothermia on blood loss and transfusion requirement. Anesthesiology 108(1):71-77

166. Pu Y, Cen G, Sun J, Gong J, Zhang Y, Zhang M et al (2014) Warming with an underbody warming system reduces intraoperative hypothermia in patients undergoing laparoscopic gastrointestinal surgery: a randomized controlled study. Int J Nurs Stud 51(2):181-189

167. Lau A, Lowlaavar N, Cooke EM, West N, German A, Morse DJ et al (2018) Effect of preoperative warming on intraoperative hypothermia: a randomized-controlled trial. Can J Anaesth 65:1029-1040

168. Connelly L, Cramer E, DeMott Q, Piperno J, Coyne B, Winfield C et al (2017) The optimal time and method for surgical prewarming: a comprehensive review of the literature. J Perianesth Nurs 32(3):199-209

169. Taguchi A, Ratnaraj J, Kabon B, Sharma N, Lenhardt R, Sessler DI et al (2004) Effects of a circulating-water garment and forced-air warming on body heat content and core temperature. Anesthesiology 100(5):1058-1064

170. Perez-Protto S, Sessler DI, Reynolds LF, Bakri MH, Mascha E, Cywinski J et al (2010) Circulating-water garment or the combination of a circulating-water mattress and forced-air cover to maintain core temperature during major upper-abdominal surgery. Br J Anaesth 105(4):466-470

171. Ljungqvist $O$ (2010) Insulin resistance and outcomes in surgery. J Clin Endocrinol Metab 95(9):4217-4219

172. Ljungqvist O, Jonathan E (2012) Rhoads lecture 2011: insulin resistance and enhanced recovery after surgery. JPEN J Parenter Enter Nutr 36(4):389-398

173. Eshuis WJ, Hermanides J, van Dalen JW, van Samkar G, Busch OR, van Gulik TM et al (2011) Early postoperative hyperglycemia is associated with postoperative complications after pancreatoduodenectomy. Ann Surg 253(4):739-744

174. Gustafsson UO, Thorell A, Soop M, Ljungqvist O, Nygren J (2009) Haemoglobin A1c as a predictor of postoperative hyperglycaemia and complications after major colorectal surgery. Br J Surg 96(11):1358-1364

175. Jones CE, Graham LA, Morris MS, Richman JS, Hollis RH, Wahl TS et al (2017) Association between preoperative hemoglobin A1c levels, postoperative hyperglycemia, and readmissions following gastrointestinal surgery. JAMA Surg 152(11):1031-1038

176. van den Berghe G, Wouters P, Weekers F, Verwaest C, Bruyninckx F, Schetz M et al (2001) Intensive insulin therapy in critically ill patients. N Engl J Med 345(19):1359-1367

177. Takesue Y, Tsuchida T (2017) Strict glycemic control to prevent surgical site infections in gastroenterological surgery. Ann Gastroenterol Surg 1(1):52-59

178. Okabayashi T, Shima Y, Sumiyoshi T, Kozuki A, Tokumaru T, Iiyama $\mathrm{T}$ et al (2014) Intensive versus intermediate glucose control in surgical intensive care unit patients. Diabetes Care 37(6):1516-1524

179. Feldheiser A, Aziz O, Baldini G, Cox BP, Fearon KC, Feldman LS et al (2016) Enhanced Recovery After Surgery (ERAS) for gastrointestinal surgery, part 2: consensus statement for anaesthesia practice. Acta Anaesthesiol Scand 60(3):289-334

180. Investigators N-SS, Finfer S, Chittock DR, Su SY, Blair D, Foster D et al (2009) Intensive versus conventional glucose control in critically ill patients. $N$ Engl J Med 360(13):1283-1297

181. Investigators N-SS, Finfer S, Liu B, Chittock DR, Norton R, Myburgh JA et al (2012) Hypoglycemia and risk of death in critically ill patients. N Engl J Med 367(12):1108-1118

182. Griesdale DE, de Souza RJ, van Dam RM, Heyland DK, Cook DJ, Malhotra A et al (2009) Intensive insulin therapy and mortality among critically ill patients: a meta-analysis including NICE-SUGAR study data. CMAJ 180(8):821-827

183. Okabayashi T, Nishimori I, Yamashita K, Sugimoto T, Maeda $\mathrm{H}$, Yatabe $\mathrm{T}$ et al (2009) Continuous postoperative blood glucose monitoring and control by artificial pancreas in patients having pancreatic resection: a prospective randomized clinical trial. Arch Surg 144(10):933-937

184. Wei ZW, Li JL, Li ZS, Hao YT, He YL, Chen W et al (2014) Systematic review of nasogastric or nasojejunal decompression after gastrectomy for gastric cancer. Eur J Surg Oncol 40(12): 1763-1770

185. Wang D, Li T, Yu J, Hu Y, Liu H, Li G (2015) Is nasogastric or nasojejunal decompression necessary following gastrectomy for gastric cancer? A systematic review and meta-analysis of randomised controlled trials. J Gastrointest Surg 19(1):195-204

186. Ding J, Liao G, Xia Y, Zhang ZM, Pan Y, Liu S et al (2013) The necessity of indwelling gastrointestinal decompression after gastrectomy: a meta-analysis. J Surg Res 179(1):e71-e81

187. Vermeulen H, Storm-Versloot MN, Busch OR, Ubbink DT (2006) Nasogastric intubation after abdominal surgery: a metaanalysis of recent literature. Arch Surg 141(3):307-314

188. Rao W, Zhang X, Zhang J, Yan R, Hu Z, Wang Q (2011) The role of nasogastric tube in decompression after elective colon and rectum surgery: a meta-analysis. Int $\mathbf{J}$ Colorectal Dis 26(4):423-429

189. Braga M, Pecorelli N, Ariotti R, Capretti G, Greco M, Balzano $G$ et al (2014) Enhanced recovery after surgery pathway in patients undergoing pancreaticoduodenectomy. World J Surg 38(11):2960-2966. https://doi.org/10.1007/s00268-014-2653-5

190. Zouros E, Liakakos T, MacHairas A, Patapis P, Agalianos C, Dervenis C (2016) Improvement of gastric emptying by enhanced recovery after pancreaticoduodenectomy. Hepatobiliary Pancreat Dis Int 15(2):198-208

191. Roland CL, Mansour JC, Schwarz RE (2012) Routine nasogastric decompression is unnecessary after pancreatic resections. Arch Surg 147(3):287-289

192. Fisher WE, Hodges SE, Cruz G, Artinyan A, Silberfein EJ, Ahern $\mathrm{CH}$ et al (2011) Routine nasogastric suction may be unnecessary after a pancreatic resection. HPB 13(11):792-796

193. Choi YY, Kim J, Seo D, Choi D, Kim MJ, Kim JH et al (2011) Is routine nasogastric tube insertion necessary in pancreaticoduodenectomy? J Korean Surg Soc 81(4):257-262

194. Kwon H, Kim S, Chun J, Hwang Y, Yun Y (2012) Is routine insertion of nasogastric tube really necessary in elective pancreatoduodenectomy?: a prospective randomized controlled trial. HPB 14:341

195. Kunstman JW, Klemen ND, Fonseca AL, Araya DL, Salem RR (2013) Nasogastric drainage may be unnecessary after pancreaticoduodenectomy: a comparison of routine vs selective decompression. J Am Coll Surg 217(3):481-488

196. Park JS, Kim JY, Kim JK, Yoon DS (2016) Should gastric decompression be a routine procedure in patients who undergo pylorus-preserving pancreatoduodenectomy? World J Surg 40(11):2766-2770. https://doi.org/10.1007/s00268-016-3604-0

197. Eng OS, Goswami J, Moore D, Chen C, Gannon CJ, August DA et al (2013) Intraoperative fluid administration is associated with perioperative outcomes in pancreaticoduodenectomy: a single center retrospective analysis. J Surg Oncol 108(4):242-247

198. Wang S, Wang X, Dai H, Han J, Li N, Li J (2014) The effect of intraoperative fluid volume administration on pancreatic fistulas after pancreaticoduodenectomy. J Investig Surg 27(2):88-94

199. Weinberg L, Wong D, Karalapillai D, Pearce B, Tan CO, Tay S et al (2014) The impact of fluid intervention on complications and length of hospital stay after pancreaticoduodenectomy (Whipple's procedure). BMC Anesthesiol 14:35 
200. Wright GP, Koehler TJ, Davis AT, Chung MH (2014) The drowning whipple: perioperative fluid balance and outcomes following pancreaticoduodenectomy. J Surg Oncol 110(4):407-411

201. Behman R, Hanna S, Coburn N, Law C, Cyr DP, Truong J et al (2015) Impact of fluid resuscitation on major adverse events following pancreaticoduodenectomy. Am J Surg 210(5):896-903

202. Healy MA, McCahill LE, Chung M, Berri R, Ito H, Obi SH et al (2016) Intraoperative fluid resuscitation strategies in pancreatectomy: results from 38 hospitals in Michigan. Ann Surg Oncol 23(9):3047-3055

203. Kulemann B, Fritz M, Glatz T, Marjanovic G, Sick O, Hopt UT et al (2017) Complications after pancreaticoduodenectomy are associated with higher amounts of intra- and postoperative fluid therapy: a single center retrospective cohort study. Ann Med Surg 16:23-29

204. Bruns H, Kortendieck V, Raab HR, Antolovic D (2016) Intraoperative fluid excess is a risk factor for pancreatic fistula after partial pancreaticoduodenectomy. HPB Surg 2016:1601340

205. Han I, Kim H, Lee J, Oh M, Lee S, Choi Y et al (2017) Excessive intraoperative fluid volume administration is associated with pancreatic fistula after pancreatoduodenectomy: a retrospective multicenter study. J Hepato-Biliary-Pancreat Sci 24:A168

206. Winer LK, Dhar VK, Wima K, Lee TC, Morris MC, Shah SA et al (2018) Perioperative net fluid balance predicts pancreatic fistula after pancreaticoduodenectomy. J Gastrointest Surg 04:04

207. Fischer M, Matsuo K, Gonen M, Grant F, Dematteo RP, D'Angelica MI et al (2010) Relationship between intraoperative fluid administration and perioperative outcome after pancreaticoduodenectomy: results of a prospective randomized trial of acute normovolemic hemodilution compared with standard intraoperative management. Ann Surg 252(6):952-958

208. Lavu H, Sell NM, Carter TI, Winter JM, Maguire DP, Gratch DM et al (2014) The HYSLAR trial: a prospective randomized controlled trial of the use of a restrictive fluid regimen with $3 \%$ hypertonic saline versus lactated Ringers in patients undergoing pancreaticoduodenectomy. Ann Surg 260(3):445-453 discussion 53-5

209. van Samkar G, Eshuis WJ, Bennink RJ, van Gulik TM, Dijkgraaf MG, Preckel B et al (2015) Intraoperative fluid restriction in pancreatic surgery: a double blinded randomised controlled trial. PLoS ONE [Electronic Resource] 10(10):e0140294

210. Chen BP, Chen M, Bennett S, Lemon K, Bertens KA, Balaa FK et al (2018) Systematic review and meta-analysis of restrictive perioperative fluid management in pancreaticoduodenectomy. World J Surg 20:20. https://doi.org/10.1007/s00268-018-4545-6

211. Grant F, Brennan MF, Allen PJ, DeMatteo RP, Kingham TP, D'Angelica M et al (2016) Prospective randomized controlled trial of liberal vs restricted perioperative fluid management in patients undergoing pancreatectomy. Ann Surg 264(4):591-598

212. Weinberg L, Ianno D, Churilov L, Chao I, Scurrah N, Rachbuch C et al (2017) Restrictive intraoperative fluid optimisation algorithm improves outcomes in patients undergoing pancreaticoduodenectomy: a prospective multicentre randomized controlled trial. PLoS ONE 12(9):e0183313

213. Rollins KE, Lobo DN (2016) Intraoperative goal-directed fluid therapy in elective major abdominal surgery: a meta-analysis of randomized controlled trials. Ann Surg 263(3):465-476

214. Conlon KC, Labow D, Leung D, Smith A, Jarnagin W, Coit DG et al (2001) Prospective randomized clinical trial of the value of intraperitoneal drainage after pancreatic resection. Ann Surg 234(4):487-493 discussion 93-4

215. Witzigmann H, Diener MK, Kienkotter S, Rossion I, Bruckner $\mathrm{T}$, Barbel $\mathrm{W}$ et al (2016) No need for routine drainage after pancreatic head resection: the dual-center, randomized, controlled PANDRA trial (ISRCTN04937707). Ann Surg 264(3):528-537

216. Van Buren G 2nd, Bloomston M, Hughes SJ, Winter J, Behrman SW, Zyromski NJ et al (2014) A randomized prospective multicenter trial of pancreaticoduodenectomy with and without routine intraperitoneal drainage. Ann Surg 259(4):605-612

217. Callery MP, Pratt WB, Kent TS, Chaikof EL, Vollmer CM Jr (2013) A prospectively validated clinical risk score accurately predicts pancreatic fistula after pancreatoduodenectomy. J Am Coll Surg 216(1):1-14

218. McMillan MT, Fisher WE, Van Buren G 2nd, McElhany A, Bloomston M, Hughes SJ et al (2015) The value of drains as a fistula mitigation strategy for pancreatoduodenectomy: something for everyone? Results of a randomized prospective multiinstitutional study. J Gastrointest Surg 19(1):21-30 discussion-1

219. Bassi C, Molinari E, Malleo G, Crippa S, Butturini G, Salvia R et al (2010) Early versus late drain removal after standard pancreatic resections: results of a prospective randomized trial. Ann Surg 252(2):207-214

220. Ven Fong Z, Correa-Gallego C, Ferrone CR, Veillette GR, Warshaw AL, Lillemoe KD et al (2015) Early drain removalthe middle ground between the drain versus no drain debate in patients undergoing pancreaticoduodenectomy: a prospective validation study. Ann Surg 262(2):378-383

221. Maggino L, Malleo G, Bassi C, Allegrini V, Beane JD, Beckman RM et al (2017) Identification of an optimal cut-off for drain fluid amylase on postoperative day 1 for predicting clinically relevant fistula after distal pancreatectomy: a multi-institutional analysis and external validation. Ann Surg 21:21

222. Beane JD, House MG, Ceppa EP, Dolejs SC, Pitt HA (2017) Variation in drain management after pancreatoduodenectomy: early versus delayed removal. Ann Surg 23:23

223. McMillan MT, Malleo G, Bassi C, Allegrini V, Casetti L, Drebin JA et al (2017) Multicenter, prospective trial of selective drain management for pancreatoduodenectomy using risk stratification. Ann Surg 265(6):1209-1218

224. Allen PJ, Gönen M, Brennan MF, Bucknor AA, Robinson LM, Pappas MM et al (2014) Pasireotide for postoperative pancreatic fistula. N Engl J Med 370(21):2014-2022

225. El Nakeeb A, ElGawalby A, Ali MA, Shehta A, Hamed H, El Refea M et al (2018) Efficacy of octreotide in the prevention of complications after pancreaticoduodenectomy in patients with soft pancreas and non-dilated pancreatic duct: a prospective randomized trial. Hepatobiliary Pancreat Dis Int 17(1):59-63

226. Dominguez-Rosado I, Fields RC, Woolsey CA, Williams G, Horwedel TA, Rose JB et al (2018) Prospective evaluation of pasireotide in patients undergoing pancreaticoduodenectomy: the Washington University experience. J Am Coll Surg 226(2):147-54.e1

227. Kurumboor P, Palaniswami KN, Pramil K, George D, Ponnambathayil S, Varma D et al (2015) Octreotide Does not prevent pancreatic fistula following pancreatoduodenectomy in patients with soft pancreas and non-dilated duct: a prospective randomized controlled trial. J Gastrointest Surg 19(11):2038-2044

228. Fernandez-Cruz L, Jimenez Chavarria E, Taura P, Closa D, Boado MA, Ferrer J (2013) Prospective randomized trial of the effect of octreotide on pancreatic juice output after pancreaticoduodenectomy in relation to histological diagnosis, duct size and leakage. HPB 15(5):392-399

229. Graham J, Johnson L, Haddad N, Al-Kawas F, Carroll J, Jha R et al (2011) A prospective study of prophylactic long-acting octreotide in high-risk patients undergoing pancreaticoduodenectomy. Am J Surg 201(4):481-485 
230. Kollmar O, Moussavian MR, Richter S, de Roi P, Maurer CA, Schilling MK (2008) Prophylactic octreotide and delayed gastric emptying after pancreaticoduodenectomy: results of a prospective randomized double-blinded placebo-controlled trial. Eur $\mathbf{J}$ Surg Oncol 34(8):868-875

231. Ramos-De la Medina A, Sarr MG (2006) Somatostatin analogues in the prevention of pancreas-related complications after pancreatic resection. J Hepato-Biliary-Pancreat Surg 13(3):190-193

232. Hesse UJ, De Decker C, Houtmeyers P, Demetter P, Ceelen W, Pattyn $\mathrm{P}$ et al (2005) Prospectively randomized trial using perioperative low dose octreotide to prevent organ related and general complications following pancreatic surgery and pancreatico-jejunostomy. Acta Chir Belg 105(4):383-387

233. Shan YS, Sy ED, Tsai ML, Tang LY, Li PS, Lin PW (2005) Effects of somatostatin prophylaxis after pylorus-preserving pancreaticoduodenectomy: increased delayed gastric emptying and reduced plasma motilin. World J Surg 29(10):1319-1324. https://doi.org/10.1007/s00268-005-7943-5

234. Shan YS, Sy ED, Lin PW (2003) Role of somatostatin in the prevention of pancreatic stump-related morbidity following elective pancreaticoduodenectomy in high-risk patients and elimination of surgeon-related factors: prospective, randomized, controlled trial. World J Surg 27(6):709-714. https://doi.org/10. 1007/s00268-003-6693-5

235. Yeo CJ, Cameron JL, Lillemoe KD, Sauter PK, Coleman J, Sohn TA et al (2000) Does prophylactic octreotide decrease the rates of pancreatic fistula and other complications after pancreaticoduodenectomy? Results of a prospective randomized placebo-controlled trial. Ann Surg 232(3):419-429

236. Koti R, Gurusamy K, Fusai G, Davidson B (2010) Meta-analysis of randomized controlled trials on the effectiveness of somatostatin analogues for pancreatic surgery: a Cochrane review (Structured abstract). HPB 12(3):155-165

237. Søreide K, Labori KJ (2016) Risk factors and preventive strategies for post-operative pancreatic fistula after pancreatic surgery: a comprehensive review. Scand J Gastroenterol 51(10):1147-1154

238. Hashimoto D, Chikamoto A, Ohmuraya M, Hirota M, Baba H (2014) Pancreaticodigestive anastomosis and the postoperative management strategies to prevent postoperative pancreatic fistula formation after pancreaticoduodenectomy. Surg Today 44(7):1207-1213

239. Drymousis P, Pai M, Spalding D, Jiao LR, Habib N, Zacharakis E (2013) Is octreotide beneficial in patients undergoing pancreaticoduodenectomy? Best evidence topic (BET). Int J Surg 11(9):779-782

240. Čečka F, Jon B, Šubrt Z, Ferko A (2012) The effect of somatostatin and its analogs in the prevention of pancreatic fistula after elective pancreatic surgery. Eur Surg Acta Chir Austriaca 44(2):99-108

241. Lai EC, Lau SH, Lau WY (2009) Measures to prevent pancreatic fistula after pancreatoduodenectomy: a comprehensive review. Arch Surg 144(11):1074-1080

242. Poon RT, Fan ST (2008) Decreasing the pancreatic leak rate after pancreaticoduodenectomy. Adv Surg 42:33-48

243. Poon RT, Lo SH, Fong D, Fan ST, Wong J (2002) Prevention of pancreatic anastomotic leakage after pancreaticoduodenectomy. Am J Surg 183(1):42-52

244. Andrén-Sandberg $\AA$, Flati G, Büchler M (2000) The role of octreotide in preventing complications after pancreatoduodenectomy for cancer. HPB 2(3):299-312

245. Li-Ling J, Irving M (2001) Somatostatin and octreotide in the prevention of postoperative pancreatic complications and the treatment of enterocutaneous pancreatic fistulas: a systematic review of randomized controlled trials. Br J Surg 88(2):190-199
246. Gurusamy KS, Koti R, Fusai G, Davidson BR (2012) Somatostatin analogues for pancreatic surgery. Cochrane Database Syst Rev 6:CD008370

247. Gurusamy KS, Koti R, Fusai G, Davidson BR (2013) Somatostatin analogues for pancreatic surgery. Cochrane Database Syst Rev 4:CD008370

248. McPhail MJ, Abu-Hilal M, Johnson CD (2006) A meta-analysis comparing suprapubic and transurethral catheterization for bladder drainage after abdominal surgery. $\mathrm{Br} \quad \mathrm{J} \quad$ Surg 93(9): 1038-1044

249. Beane JD, House MG, Miller A, Nakeeb A, Schmidt CM, Zyromski NJ et al (2014) Optimal management of delayed gastric emptying after pancreatectomy: an analysis of 1089 patients. Surgery 156(4):939-946

250. El Nakeeb A, Askr W, Mahdy Y, Elgawalby A, El Sorogy M, Abu Zeied M et al (2015) Delayed gastric emptying after pancreaticoduodenectomy. Risk factors, predictors of severity and outcome. A single center experience of 588 cases. J Gastrointest Surg 19(6): 1093-1100

251. Liu QY, Li L, Xia HT, Zhang WZ, Cai SW, Lu SC (2016) Risk factors of delayed gastric emptying following pancreaticoduodenectomy. ANZ J Surg 86(1-2):69-73

252. Sato G, Ishizaki Y, Yoshimoto J, Sugo H, Imamura H, Kawasaki S (2014) Factors influencing clinically significant delayed gastric emptying after subtotal stomach-preserving pancreatoduodenectomy. World J Surg 38(4):968-975. https://doi.org/10. 1007/s00268-013-2288-y.

253. Wente MN, Bassi C, Dervenis C, Fingerhut A, Gouma DJ, Izbicki JR et al (2007) Delayed gastric emptying (DGE) after pancreatic surgery: a suggested definition by the International Study Group of Pancreatic Surgery (ISGPS). Surgery 142(5):761-768

254. Parmar AD, Sheffield KM, Vargas GM, Pitt HA, Kilbane EM, Hall BL et al (2013) Factors associated with delayed gastric emptying after pancreaticoduodenectomy. HPB 15(10):763-772

255. Qu H, Sun GR, Zhou SQ, He QS (2013) Clinical risk factors of delayed gastric emptying in patients after pancreaticoduodenectomy: a systematic review and meta-analysis. Eur J Surg Oncol 39(3):213-223

256. Glowka TR, Webler M, Matthaei H, Schafer N, Schmitz V, Kalff JC et al (2017) Delayed gastric emptying following pancreatoduodenectomy with alimentary reconstruction according to Roux-en-Y or Billroth-II. BMC Surg 17(1):24

257. Huttner FJ, Klotz R, Ulrich A, Buchler MW, Diener MK (2016) Antecolic versus retrocolic reconstruction after partial pancreaticoduodenectomy. Cochrane Database Syst Rev 9:CD011862

258. Tamandl D, Sahora K, Prucker J, Schmid R, Holst JJ, Miholic J et al (2014) Impact of the reconstruction method on delayed gastric emptying after pylorus-preserving pancreaticoduodenectomy: a prospective randomized study. World J Surg 38(2):465-475. https://doi.org/10.1007/s00268-013-2274-4

259. Lei P, Fang J, Huang Y, Zheng Z, Wei B, Wei H (2014) Pancreaticogastrostomy or pancreaticojejunostomy? Methods of digestive continuity reconstruction after pancreaticodudenectomy: a meta-analysis of randomized controlled trials. Int J Surg 12(12): 1444-1449

260. Ma S, Li Q, Dai W, Pan F (2014) Pancreaticogastrostomy versus pancreaticojejunostomy. J Surg Res 192(1):68-75

261. Hackert T, Probst P, Knebel P, Doerr-Harim C, Bruckner T, Klaiber U et al (2018) Pylorus resection does not reduce delayed gastric emptying after partial pancreatoduodenectomy: a blinded randomized controlled Trial (PROPP Study, DRKS00004191). Ann Surg 267(6):1021-1027

262. Lei P, Wei B, Guo W, Wei H (2014) Minimally invasive surgical approach compared with open pancreaticoduodenectomy: 
a systematic review and meta-analysis on the feasibility and safety. Surg Laparosc Endosc Percutaneous Tech 24(4):296-305

263. Mohammed S, Van Buren Ii G, McElhany A, Silberfein EJ, Fisher WE (2017) Delayed gastric emptying following pancreaticoduodenectomy: incidence, risk factors, and healthcare utilization. World J Gastrointest Surg 9(3):73-81

264. Futagawa Y, Kanehira M, Furukawa K, Kitamura H, Yoshida S, Usuba $\mathrm{T}$ et al (2017) Impact of delayed gastric emptying after pancreaticoduodenectomy on survival. J Hepato-Biliary-Pancreat Sci 24(8):466-474

265. Liu C, Du Z, Lou C, Wu C, Yuan Q, Wang J et al (2011) Enteral nutrition is superior to total parenteral nutrition for pancreatic cancer patients who underwent pancreaticoduodenectomy. Asia Pac J Clin Nutr 20(2):154-160

266. Liu Q, Jiang H, Xu D, Jin J (2017) Effect of gum chewing on ameliorating ileus following colorectal surgery: a meta-analysis of 18 randomized controlled trials. Int J Surg 47:107-115

267. Li S, Liu Y, Peng Q, Xie L, Wang J, Qin X (2013) Chewing gum reduces postoperative ileus following abdominal surgery: a meta-analysis of 17 randomized controlled trials. J Gastroenterol Hepatol 28(7):1122-1132

268. Andersson T, Bjersa K, Falk K, Olsen MF (2015) Effects of chewing gum against postoperative ileus after pancreaticoduodenectomy-a randomized controlled trial. BMC Res Notes 8:37

269. Lee CH, Kim H, Han IW, Kim SM, Kwak BS, Baik YH et al (2016) Effect of polylactic film (Surgi-Wrap) on preventing postoperative ileus after major hepato-pancreato-biliary surgery. Ann Hepato-Biliary-Pancreat Surg 20(4):191-196

270. Kumar S, Wong PF, Leaper DJ (2009) Intra-peritoneal prophylactic agents for preventing adhesions and adhesive intestinal obstruction after non-gynaecological abdominal surgery. Cochrane Database Syst Rev 1:CD005080

271. Xu LL, Zhou XQ, Yi PS, Zhang M, Li J, Xu MQ (2016) Alvimopan combined with enhanced recovery strategy for managing postoperative ileus after open abdominal surgery: a systematic review and meta-analysis. J Surg Res 203(1):211-221

272. Drake TM, Ward AE (2016) Pharmacological management to prevent ileus in major abdominal surgery: a systematic review and meta-analysis. J Gastrointest Surg 20(6):1253-1264

273. Vaughan-Shaw PG, Fecher IC, Harris S, Knight JS (2012) A meta-analysis of the effectiveness of the opioid receptor antagonist alvimopan in reducing hospital length of stay and time to GI recovery in patients enrolled in a standardized accelerated recovery program after abdominal surgery. Dis Colon Rectum 55(5):611-620

274. Earnshaw SR, Kauf TL, McDade C, Potashman MH, Pauyo C, Reese ES et al (2015) Economic impact of alvimopan considering varying definitions of postoperative ileus. J Am Coll Surg 221(5):941-950

275. Traut U, Brugger L, Kunz R, Pauli-Magnus C, Haug K, Bucher $\mathrm{HC}$ et al (2008) Systemic prokinetic pharmacologic treatment for postoperative adynamic ileus following abdominal surgery in adults. Cochrane Database Syst Rev 1:CD004930

276. Narita K, Tsunoda A, Takenaka K, Watanabe M, Nakao K, Kusano M (2008) Effect of mosapride on recovery of intestinal motility after hand-assisted laparoscopic colectomy for carcinoma. Dis Colon Rectum 51(11):1692-1695

277. Toyomasu Y, Mochiki E, Morita H, Ogawa A, Yanai M, Ohno T et al (2011) Mosapride citrate improves postoperative ileus of patients with colectomy. J Gastrointest Surg 15(8):1361-1367

278. Bozzetti F, Mariani L (2014) Perioperative nutritional support of patients undergoing pancreatic surgery in the age of ERAS. Nutrition 30(11-12):1267-1271
279. Buscemi S, Damiano G, Palumbo VD, Spinelli G, Ficarella S, Lo Monte $\mathrm{G}$ et al (2015) Enteral nutrition in pancreaticoduodenectomy: a literature review. Nutrients 7(5):3154-3165

280. Akizuki E, Kimura Y, Nobuoka T, Imamura M, Nagayama M, Sonoda $\mathrm{T}$ et al (2009) Reconsideration of postoperative oral intake tolerance after pancreaticoduodenectomy: prospective consecutive analysis of delayed gastric emptying according to the ISGPS definition and the amount of dietary intake. Ann Surg 249(6):986-994

281. Lassen K, Revhaug A (2006) Early oral nutrition after major upper gastrointestinal surgery: why not? Curr Opin Clin Nutr Metab Care 9(5):613-617

282. Gerritsen A, Besselink MG, Gouma DJ, Steenhagen E, Borel Rinkes IH, Molenaar IQ (2013) Systematic review of five feeding routes after pancreatoduodenectomy. $\mathrm{Br} \quad \mathrm{J}$ Surg 100(5):589-598 discussion 99

283. Gerritsen A, Wennink RAW, Besselink MGH, Van Santvoort HC, Tseng DSJ, Steenhagen E et al (2014) Early oral feeding after pancreatoduodenectomy enhances recovery without increasing morbidity. HPB 16(7):656-664

284. Lassen K, Kjaeve J, Fetveit T, Trano G, Sigurdsson HK, Horn A et al (2008) Allowing normal food at will after major upper gastrointestinal surgery does not increase morbidity: a randomized multicenter trial. Ann Surg 247(5):721-729

285. Fujii T, Nakao A, Murotani K, Okamura Y, Ishigure K, Hatsuno $T$ et al (2015) Influence of food intake on the healing process of postoperative pancreatic fistula after pancreatoduodenectomy: a multi-institutional randomized controlled trial. Ann Surg Oncol 22(12):3905-3912

286. Braga M, Capretti G, Pecorelli N, Balzano G, Doglioni C, Ariotti R et al (2011) A prognostic score to predict major complications after pancreaticoduodenectomy. Ann Surg 254(5):702-707 discussion 7-8

287. Gerritsen A, Besselink MG, Cieslak KP, Vriens MR, Steenhagen E, van Hillegersberg R et al (2012) Efficacy and complications of nasojejunal, jejunostomy and parenteral feeding after pancreaticoduodenectomy. J Gastrointest Surg 16(6):1144-1151

288. Padussis JC, Zani S, Blazer DG, Tyler DS, Pappas TN, Scarborough JE (2014) Feeding jejunostomy during Whipple is associated with increased morbidity. J Surg Res 187(2):361-366

289. Waliye HE, Wright GP, McCarthy C, Johnson J, Scales A, Wolf A et al (2017) Utility of feeding jejunostomy tubes in pancreaticoduodenectomy. Am J Surg 213(3):530-533

290. Gilliland TM, Villafane-Ferriol N, Shah KP, Shah RM, Tran Cao HS, Massarweh NN et al (2017) Nutritional and metabolic derangements in pancreatic cancer and pancreatic resection. Nutrients 9(3):07

291. Qinghua W, Qiangpu C (2012) Jejunal tube feeding and pancreatoduodenectomy. 59(120):2653-2656

Hepatogastroenterology

292. Seres DS, Valcarcel M, Guillaume A (2013) Advantages of enteral nutrition over parenteral nutrition. Ther Adv Gastroenterol 6(2):157-167

293. Zhao XF, Wu N, Zhao GQ, Liu JF, Dai YF (2016) Enteral nutrition versus parenteral nutrition after major abdominal surgery in patients with gastrointestinal cancer: a systematic review and meta-analysis. J Investig Med 64(5):1061-1074

294. Lee SH, Lee JG (2016) Early enteral nutrition still has advantages in patients undergoing pancreaticoduodenectomy. J Thorac Dis 8(10):E1340-E1342

295. Lu JW, Liu C, Du ZQ, Liu XM, Lv Y, Zhang XF (2016) Early enteral nutrition vs parenteral nutrition following pancreaticoduodenectomy: experience from a single center. World J Gastroenterol 22(14):3821-3828 
296. Perinel J, Mariette C, Dousset B, Sielezneff I, Gainant A, Mabrut $J$ et al (2016) Early enteral versus total parenteral nutrition in patients undergoing panreaticoduodenectomy: a randomized multicenter controlled trial (NUTRI DPC). United Eur Gastroenterol J 4(5 Supplement 1):A92-a3

297. Probst P, Keller D, Steimer J, Gmur E, Haller A, Imoberdorf R et al (2016) Early combined parenteral and enteral nutrition for pancreaticoduodenectomy-retrospective cohort analysis. Ann Med Surg 6:68-73

298. Zhu X, Wu Y, Qiu Y, Jiang C, Ding Y (2014) Comparative analysis of the efficacy and complications of nasojejunal and jejunostomy on patients undergoing pancreaticoduodenectomy. Jpen J Parenter Enter Nutr 38(8):996-1002

299. Okabayashi T, Kobayashi M, Nishimori I, Sugimoto T, Akimori T, Namikawa $T$ et al (2006) Benefits of early postoperative jejunal feeding in patients undergoing duodenohemipancreatectomy. World J Gastroenterol 12(1):89-93

300. Brower RG (2009) Consequences of bed rest. Crit Care Med 37(10 Suppl):S422-S428

301. Castelino T, Fiore JF Jr, Niculiseanu P, Landry T, Augustin B, Feldman LS (2016) The effect of early mobilization protocols on postoperative outcomes following abdominal and thoracic surgery: a systematic review. Surgery 159(4):991-1003

302. Fiore JF Jr, Castelino T, Pecorelli N, Niculiseanu P, Balvardi S, Hershorn $\mathrm{O}$ et al (2017) Ensuring early mobilization within an enhanced recovery program for colorectal surgery: a randomized controlled trial. Ann Surg 266(2):223-231

303. Coolsen MM, van Dam RM, van der Wilt AA, Slim K, Lassen K, Dejong CH (2013) Systematic review and meta-analysis of enhanced recovery after pancreatic surgery with particular emphasis on pancreaticoduodenectomies. World J Surg 37(8):1909-1918. https://doi.org/10.1007/s00268-013-2044-3

304. Morales Soriano R, Esteve Perez N, Tejada Gavela S, Cuadrado Garcia A, Rodriguez Pino JC, Moron Canis JM et al (2015) Outcomes of an enhanced recovery after surgery programme for pancreaticoduodenectomy. Cir Esp 93(8):509-515

305. Vollmer CM, Asbun HJ, Barkun J, Besselink MG, Boggi U, Conlon KC et al (2017) Proceedings of the first international state-of-the-art conference on minimally-invasive pancreatic resection (MIPR). HPB (Oxford) 19(3):171-177

306. Edwin B, Sahakyan MA, Abu Hilal M, Besselink MG, Braga M, Fabre JM et al (2017) Laparoscopic surgery for pancreatic neoplasms: the European association for endoscopic surgery clinical consensus conference. Surg Endosc 31(5):2023-2041

307. Takagi K, Yoshida R, Yagi T, Umeda Y, Nobuoka D, Kuise T et al (2018) Effect of an enhanced recovery after surgery protocol in patients undergoing pancreaticoduodenectomy: a randomized controlled trial. Clin Nutr (Edinburgh, Scotland). http:// cochranelibrary-wiley.com/o/cochrane/clcentral/articles/089/ CN-01450089/frame.html
308. Poves I, Burdio F, Morato O, Iglesias M, Radosevic A, Ilzarbe L et al (2018) Comparison of perioperative outcomes between laparoscopic and open approach for pancreatoduodenectomy: the PADULAP randomized controlled trial. Ann Surg 268(5):731-739

309. Palanivelu C, Senthilnathan P, Sabnis SC, Babu NS, Srivatsan Gurumurthy S, Anand Vijai N et al (2017) Randomized clinical trial of laparoscopic versus open pancreatoduodenectomy for periampullary tumours. Br J Surg 104(11):1443-1450

310. de Rooij T, van Hilst J, Bosscha K, Dijkgraaf MG, Gerhards MF, Groot Koerkamp B et al (2018) Minimally invasive versus open pancreatoduodenectomy (LEOPARD-2): study protocol for a randomized controlled trial. Trials 19(1):1

311. van Hilst J, de Rooij T, Bosscha K, Brinkman DJ, van Dieren S, Dijkgraaf MG et al (2019) Laparoscopic versus open pancreatoduodenectomy for pancreatic or periampullary tumours (LEOPARD-2): a multicentre, patient-blinded, randomised controlled phase 2/3 trial. Lancet Gastroenterol Hepatol 4(3):199-207

312. Adam MA, Thomas S, Youngwirth L, Pappas T, Roman SA, Sosa JA (2017) Defining a hospital volume threshold for minimally invasive pancreaticoduodenectomy in the United States. JAMA Surg 152(4):336-342

313. Kutlu OC, Lee JE, Katz MH, Tzeng CD, Wolff RA, Varadhachary GR et al (2018) Open pancreaticoduodenectomy case volume predicts outcome of laparoscopic approach: a population-based analysis. Ann Surg 267(3):552-560

314. Klompmaker S, van Hilst J, Wellner UF, Busch OR, Coratti A, D'Hondt $\mathrm{M}$ et al (2018) Outcomes after minimally-invasive versus open pancreatoduodenectomy: a pan-European propensity score matched study. Ann Surg 271:356-363

315. Zhao W, Liu C, Li S, Geng D, Feng Y, Sun M (2018) Safety and efficacy for robot-assisted versus open pancreaticoduodenectomy and distal pancreatectomy: a systematic review and metaanalysis. Surg Oncol 27(3):468-478

316. Ivers N, Jamtvedt G, Flottorp S, Young JM, Odgaard-Jensen J, French SD et al (2012) Audit and feedback: effects on professional practice and healthcare outcomes. Cochrane Database Syst Rev 6:CD000259

317. Tuti T, Nzinga J, Njoroge M, Brown B, Peek N, English M et al (2017) A systematic review of electronic audit and feedback: intervention effectiveness and use of behaviour change theory. Implement Sci 12(1):61

318. Francis NK, Walker T, Carter F, Hubner M, Balfour A, Jakobsen DH et al (2018) Consensus on training and implementation of enhanced recovery after surgery: a delphi study. World J Surg 42(7):1919-1928. https://doi.org/10.1007/s00268-017-4436-2

Publisher's Note Springer Nature remains neutral with regard to jurisdictional claims in published maps and institutional affiliations. 